Florida International University FIU Digital Commons

FCE LTER Journal Articles

FCE LTER

2006

\title{
Characteristics of surface-water flows in the ridge and slough landscape of Everglades National Park: implications for particulate transport
}

Lynn Leonard

Center for Marine Science, University of North Carolina Wilmington

Alexander L. Croft

Department of Biological Sciences, Florida International University

Dan Childers

Department of Biological Sciences, Florida International University, childers@fiu.edu

Sherry Mitchell-Bruker

Everglades National Park

Helena Solo-Gabriele

Department of Civil, Architectural, and Environmental Engineering

See next page for additional authors

Follow this and additional works at: https://digitalcommons.fiu.edu/fce_lter_journal_articles

Part of the Life Sciences Commons

\section{Recommended Citation}

Leonard, L., A.L. Croft, D.L. Childers, S. Mitchell-Bruker, H. Solo-Gabriele, M.S. Ross. 2006. Characteristics of surface-water flows in the ridge and slough landscape of Everglades National Park: implications for particulate transport. Hydrobiologia 569(1): 5-22.

This material is based upon work supported by the National Science Foundation through the Florida Coastal Everglades Long-Term Ecological Research program under Cooperative Agreements \#DBI-0620409 and \#DEB-9910514. Any opinions, findings, conclusions, or recommendations expressed in the material are those of the author(s) and do not necessarily reflect the views of the National Science Foundation. This work is brought to you for free and open access by the FCE LTER at FIU Digital Commons. It has been accepted for inclusion in FCE LTER Journal Articles by an authorized administrator of FIU Digital Commons. For more information, please contact dcc@fiu.edu, jkrefft@fiu.edu. 


\section{Authors}

Lynn Leonard, Alexander L. Croft, Dan Childers, Sherry Mitchell-Bruker, Helena Solo-Gabriele, and Michael S. Ross 
Characteristics of Surface Flows in the Ridge and Slough Landscape of Everglades National Park: Implications for Particulate Transport

Lynn Leonard, Alexander Croft, Daniel Childers, Sherry Mitchell-Bruker, Helena Solo-Gabriele and Michael Ross 


\begin{abstract}
Over the last one hundred years, compartmentalization and water management activities have reduced water flow to the ridge and slough landscape of the Everglades. As a result, the once corrugated landscape has become topographically and vegetationally uniform. The focus of this study was to quantify variations in surface flow hydrology in the ridge and slough landscape and to relate flow conditions to particulate transport and deposition. Over the 2002-2003 and 2003-2004 wet seasons, surface velocities and particulate accumulation were measured in upper Shark River Slough in Everglades National Park. Landscape characteristics such as elevation, plant densities and biomass also were examined to determine their impact on flow characteristics and material transport. The results of this study demonstrate that the release of water during the wet season not only increases water levels, but also increased flow speeds and particulate transport and availability. Further, flow speeds were positively and significantly correlated with water level thereby enhancing particulate transport in sloughs relative to ridges especially during peak flow periods. Our results also indicate that the distribution of biomass in the water column, including floating plants and periphyton, affects velocity magnitude and shape of vertical profiles; especially in the sloughs where Utricularia spp. and periphyton mats are more abundant. Plot clearing experiments suggest that the presence of surface periphyton and Utricularia exert greater control over flow characteristics than plant type (i.e. sawgrass or spike rush) or stem density; two parameters frequently incorporated into models describing flow through vegetated canopies. Based on these results, we suggest that future modeling efforts must take the presence of floating biomass, such as Utricularia, and presence of periphyton into consideration when describing particulate transport.
\end{abstract}




\section{INTRODUCTION}

A mosaic of sawgrass marsh ridges, deeper sloughs and teardrop-shaped tree islands characterizes the wetland geomorphology of much of the Florida Everglades, USA. Once extending unbroken from the south shore of Lake Okeechobee to Florida Bay and encompassing more than 10,000 $\mathrm{km}^{2}$ (Chimney and Goforth 2001), the present Everglades is only 50 percent of its original extent. The remaining landscape north of Everglades National Park has been compartmentalized into shallow, diked impoundments known as Water Conservation Areas (Davis \& Ogden 1997). The ridge and slough landscape, a major landscape type in the Everglades, is believed to have formed in response to the seasonal but once regular and uninterrupted flow downslope from Lake Okeechobee to the Gulf of Mexico (Kushlan 1993) that periodically experienced pulses of increased flow presumably in association with storms. The preservation of the corrugated wetland landscape, in which scoured sloughs maintained pathways for downstream movement of large volumes of water, has been attributed to higher historic flow rates and faster velocities moving through the deeper waters of the sloughs (Mitchell Bruker et al. 2005).

Over the last century, anthropogenic practices including compartmentalization and drainage have captured and/or diverted much of the historic water flow, thereby greatly reducing or eliminating flow in much of the Everglades and disrupting the physical, chemical and biological processes critical to maintenance of the ridge and slough landscape. As a result, compartmentalization and related water management activities are considered to be the primary cause of the degradation of the ridge sand slough landscape to one that is more topographically 
and vegetationally uniform. Nonetheless, the exact mechanisms leading to this degradation are not fully understood (SCT 2003).

Attempting to understand wetland response to these kinds of physical change is complicated and should include the complexities of wetland hydrology at a variety of scales. The focus of this work is to quantify fine scale surface hydrology within the Everglades and to determine how surface hydrology may affect the landscape characteristics within the system. Since flow rates affect particulate transport and deposition, with higher speeds potentially causing scouring of unconsolidated sediment and transport and slower speeds potentially resulting in deposition, the expectation is that higher flow speeds in the sloughs and slower speeds in the ridge should preserve a ridge and slough topography. Although little published data exist that describe surface hydrology of Everglade’s marshes, data collected in other wetland systems have shown that flow rates and other flow characteristics can control suspended particle distribution over both vertical and horizontal scales (Leonard et al. 1995, Leonard 1997, Christiansen et al. 2000 and Leonard et al. 2002). Moreover, sediment deposition on marsh surfaces is recognized to be spatially variable, with the distance a particle travels before settling out of suspension depending on the horizontal flow velocity (Leonard \& Luther 1995, Christiansen et al. 2000). Total suspended sediment concentration, length of inundation, channel morphology, and marsh topography also have been shown to have synergistic interactions over sediment dynamics in wetlands (Leonard 1997).

More recently, vegetative characteristics have been demonstrated to impact sediment and flow dynamics, as well. In east coast tidal marsh systems, surface flows have been shown to be neither fully turbulent nor fully laminar due to plant/flow interactions in velocities usually less than $10 \mathrm{~cm} \mathrm{~s}^{-1}$ (Leonard \& Luther 1995, Christiansen et al. 2000). Leonard \& Luther (1995) 
found that higher stem densities resulted in decreased flow speeds in both Juncus roemerianus and Spartina alterniflora marshes. Leonard \& Luther (1995) and Neumeier \& Ciavola (2004) also demonstrated how flow speeds within a plant canopy are reduced within the canopy relative to flow speeds above the canopy. Further, Neumeier \& Ciavola (2004) documented flow reductions correlated with local vegetation density and the absence of a logarithmic velocity profile in a Spartina maritima marsh. Additional studies have suggested that differences in canopy morphology can affect flow speed and flow energy due to variations in the way the plant material is distributed in the water column (Leonard \& Reed 2002; Neumeier \& Ciavola 2004; Harvey et al. 2005). The variations in flow have potential to increase the heterogeneity of particulate concentrations in the water column and to promote dispersion of both suspended particulates and dissolved materials (Nepf et al. 1997; Harvey et al. 2005).

Although, previous studies have described how plant/geomorphology/flow interactions can influence particulate transport in tidal wetlands (e.g. Leonard \& Luther 1995; Christiansen et al. 2000), few such detailed observations exist for freshwater wetlands (e.g. Saiers et al. 2003). Thus, important questions still remain regarding these processes in the Everglades landscape. This study was one component of a multidisciplinary effort to examine surface flow and sediment transport in and around tree islands within the upper Shark River Slough of the Everglades National Park, Florida, USA. The objectives of this project were: 1) to quantify surface flow velocities and small scale variations in surface water flow in the ridge and slough landscape, 2) to determine the effects of surface flow variability on particulate transport and deposition, and 3) to determine the effects of topography, plant type, and biomass on flow characteristics and particulate transport in this system. An improved understanding of surface flow dynamics and its effect on particle transport and deposition is relevant to the Everglades 
Restoration, one goal of which is to restore water flow to the landscape in ways that are most beneficial to ecosystem function.

\section{METHODS}

Changes in flow hydrodynamics resulting from plant/flow interactions were examined for various canopy types and various vegetation densities within upper Shark River Slough of Everglades National Park, FL (Figure 1). This ridge slough environment is dominated by emergent vegetation of spikerush (Eleocharis cellulosa and Eleocharis elongata), and sawgrass (Cladium jamaicense). Further, submerged vegetation, such as bladderworts (Utricularia foliasa and Utricularia purpurea) and periphyton mats, were present within the study area. This research was divided into three primary areas of interest: 1) Initial characterization of flow and sediment transport in slough and ridge landscapes; 2) Investigation of the extent to which plants and landscape influence hydrodynamics along a 300 meter transect which traversed a variety of different environments (Figure 1); and 3) Vegetative manipulation experiments with water velocity profiles which were conducted to determine the hydrodynamic characteristics that most strongly influence flow over the entire water column within this system.

Flow and sediment transport were initially monitored only at several stations located in spike rush sloughs and adjacent sawgrass ridges near a tree island known locally as Gumbo Limbo (Figure 1). These data were collected from Dec 02 until Feb 03 during the 2002-2003 wet season and from June 03 until Jan 04 over the 2003-2004 wet season. Fieldwork also consisted of bi-monthly transect sampling during the latter half of the 03-04 wet season from October through January. The transect extended west from Gumbo Limbo tree island, beginning 
150 meters west of the island head and ending at 440 meters (Figure 1). Water levels, water velocities, and sediment transport were measured every 10 meters along this transect. In addition, a transect elevation survey was conducted using a Leica Total Station in Dec 03. Plant surveys, consisting of stem counts by species, were conducted twice for sites along the transect and bi-monthly during the wet season for the control slough and ridge sites.

Water velocities were measured using SONTEK handheld acoustic Doppler velocimeters (SonTek Handheld FlowTracker ADV, San Diego, CA). These instruments provided reliable and accurate water velocity measurements in three dimensions for the exceedingly low velocity values characteristics of Everglades flow (e.g. $<3 \mathrm{~cm} \mathrm{~s}^{-1}$ ). Velocity measurements were taken every 10 meters along the transect at 6/10 of water depth. The ADV instrument was configured to transmit 10 acoustical signals or "pings” per second, store these 10 pings as a one second sample, and then average these data over a 40 second sampling burst. Three replicate measurements were taken at each sample location.

In the Everglades, total suspended solid concentrations are very low ( typically less than $2 \mathrm{mg} \mathrm{L}^{-1}$ ) in the water column with the exception of a 2-3 cm thick layer of organic flocculent material, produced in situ, that occurs directly above the soil surface. This material, referred to as “floc”, has a very low bulk density and is typically found as a nearly neutrally buoyant organic layer just above the soil surface. In general, floc layers are thicker in sloughs than on sawgrass ridges and this material is presumed to be transported downstream when flow velocities are sufficiently elevated. In order to examine relative differences in suspended particle transport among the ridge and slough environments in the study area, suspended sediment collection traps measuring $7 \mathrm{~cm}$ in diameter by $8 \mathrm{~cm}$ deep were deployed at each site to determine variations in particle accumulation. These sediment traps were anchored to the soil surface and left out over a 
period of 4 to 5 days. Upon retrieval sediments were dried and weighed to determine accumulation rate. Due to material limitations, sediment traps were deployed at selected locations along the Gumbo Limbo transect to optimize for different vegetative characteristics. Further, only one trap was deployed at each site. For the other slough and ridge sites, sediment traps were deployed in triplicate. A vegetative survey was conducted during Oct 03 along the Gumbo Limbo transect, and Aug 03, Oct 03, and Jan 04 at the other slough and ridge locations. A 0.5 x 0.5 meter quadrat was used for vegetative identification and stem densities by species for each station that received a sediment collection trap. Quadrat locations were selected blindly to allow for random sampling. The densities of both live and dead stems within each quadrat was measured and recorded. A transect elevation survey was conducted in Dec 03. A total elevation station was used to determine the surface elevation change for each station that received a sediment trap. Changes in topography are reported relative to (higher or lower than) the first sample site (G150).

Vegetative characteristics and manipulations were conducted to examine the importance of standing biomass and other vegetation such as floating bladderworts and periphyton mats on the Everglades flow velocities within the slough system. The influence of standing biomass on flow within the sloughs was determined by two techniques. It was first determined by quantifying stem densities by species in the locations where velocities were measured. Vegetative manipulations were also performed in a three-tiered process to investigate biomass effects on flow. This was done by first taking velocity measurements at two heights in the water column simultaneously. These measurements were taken at 12 and $38 \mathrm{~cm}$ below the water surface. Velocity was assumed to be zero at the water soil interface. Floating biomass (bladderworts and periphyton) was then removed and velocity measurements taken again. 
Finally, all standing biomass was removed from a $1 \mathrm{~m}^{2}$ area surrounding the sensors and velocities were measured for a third time.

Time series of the velocity components were used to calculate time-averaged and turbulent velocities. Turbulence intensity was computed from the standard deviation of the instantaneous velocities about the mean (Kundu 1990). For the turbulence analysis, the instantaneous downstream, cross- stream and vertical velocities (u, v, and, w, respectively) were decomposed into the time-averaged velocities $\mathrm{U}, \mathrm{V}$, and $\mathrm{W}$, and the turbulent components $\mathrm{u}_{\mathrm{t}}, \mathrm{v}_{\mathrm{t}}$, and $\mathrm{w}_{\mathrm{t}}$, using the formula $\mathrm{u}=\mathrm{U}+\mathrm{u}_{\mathrm{t}}$. The turbulence intensities $\mathrm{u}_{\mathrm{u}}, \mathrm{u}_{\mathrm{v}}$, and $\mathrm{u}_{\mathrm{w}}$ were computed as the root mean square of $\mathrm{u}_{\mathrm{t}}, \mathrm{v}_{\mathrm{t}}$, and $\mathrm{w}_{\mathrm{t}}$, respectively. The turbulent kinetic energy (TKE) was calculated from the following equation:

$$
\operatorname{TKE}=1 / 2 \rho\left(\overline{u_{t}^{2}}+\overline{v_{t}^{2}}+\overline{w_{t}^{2}}\right)
$$

where $\rho$ was the water density. In order to evaluate the effect of canopy morphology on both horizontal and vertical turbulence, TKE also was differentiated in the horizontal component ( $\mathrm{TKE}_{\text {horiz, }}$ computed from $\mathrm{u}_{\mathrm{t}}$ and $\mathrm{v}_{\mathrm{t}}$ ) and the vertical component $\left(\mathrm{TKE}_{\mathrm{vert}}\right.$, computed from $\left.\mathrm{w}_{\mathrm{t}}\right)$.

A students T-test $(\mathrm{p}<0.05)$ was used to determine significant differences between velocity means for landscape types and to determine any significant differences in sediment accumulation between ridge and slough environments. These analyses were conducted over the entire sampling period as well as for each individual sampling month.

\section{RESULTS}

\section{$\underline{\text { General Flow Characteristics and Particulate Accumulation Trends }}$}


The control slough and ridge environments were the first landscapes to be investigated in the upper Shark River Slough over the latter half of the 02-03 wet season and the entire 03-04 wet season. Flow velocities in the study area were very low, less than $2 \mathrm{~cm} \mathrm{sec}^{-1}$, and laminar to sublaminar. Velocities measured at slough sampling sites were generally higher than at sawgrass ridge sites, with mean velocities of $0.50 \mathrm{~cm} \mathrm{sec}^{-1}$ and $0.34 \mathrm{~cm} \mathrm{sec}^{-1}$, respectively (Figure 2). A ttest, however, showed no significance difference in velocity between the two landscape types over the entire study period $(\mathrm{p}=0.118, \mathrm{~F}=2.56)$.

Flow velocities at all sites exhibited seasonal variations that were related to the quantity of water in the system. The highest velocities in both the slough and ridge areas corresponded to the time of the wet season (Aug 03 and Oct 03) when water levels were also the highest (Figure 3). Maximum rates of particulate accumulation in sediment collection cups also corresponded to periods of increased water level and mean flow velocity (Figure 3). This trend was more apparent for the slough sites than the ridge sites. When the relationship between water level and flow velocity was examined for all sampling dates combined, flow velocity was significantly and positively correlated with water depths for both slough $(\mathrm{R}=0.86, \mathrm{p}<0.0001)$ and ridge $(\mathrm{R}=0.69$, $\mathrm{p}<0.005$ ) landscape types.

\section{$\underline{\text { Ridge and Slough Variations in Flow and Particulate Transport }}$}

In order to examine variations in flow over a larger scale, flow velocity, sediment trap data, and water depth were collected bi-monthly along the Gumbo Limbo transect from Oct 2003 until Jan 2004. Further, a ground surface elevation survey was conducted in Dec 2003 (Figure 4). Transects sites were classified as either slough or ridge depending on the vegetative characteristics of each sampling location. Approximately $120 \mathrm{~m}$ of the transect was classified as ridge while sloughs comprised about $170 \mathrm{~m}$ of the transect. For the most part, ridge sites were 
topographically higher than slough sites with the mean elevation of the ridge sites being approximately $12.84 \mathrm{~cm}$ higher than the slough sites. Mean water depth for the ridge and slough environments were significantly different $(\mathrm{p}<0.0001, \mathrm{~F}=44.7)$ with means of 53.6 and $61.9 \mathrm{~cm}$ in the ridge and slough environments, respectively. Over the period of Oct 2003 to Jan 2004, mean water depth decreased from 64.2 to $42.2 \mathrm{~cm}$ for the ridge sites and from 74.7 to $51.2 \mathrm{~cm}$ for the slough sites.

In spite of the greater water depths, flow speeds within the sloughs were still quite low and never exceeded $1.8 \mathrm{~cm} \mathrm{sec}^{-1}$. Flow velocities in the sloughs also showed no systematic variation with respect to position in the slough (Figure 5), although higher velocities were often observed near the center or in the topographically lowest area of the slough. These results were consistent with velocity data collected along cross-sections of other sloughs in Shark River Slough which also showed some lateral variation in flow velocity with highest velocities usually centralized in the slough (Figure 6).

Over the transect sampling period (Oct 03 - Jan 04), the overall mean daily rate of particulate accumulation in the sediment traps and the mean flow velocity measured at the ridge sites was significantly lower, $(\mathrm{p}<0.05, \mathrm{~F}=6.67$ and $\mathrm{p}<0.05, \mathrm{~F}=5.37$, respectively) than at the slough sites (Figure 7). Similar trends were observed when comparing the ridge and slough environments on a monthly interval. For example, the mean daily rate of particulate accumulation in the ridge environment $\left(44.8 \pm 18.3\right.$ S.E. $\left.g d w \mathrm{~d}^{-1} \mathrm{~m}^{-2}, \mathrm{n}=10\right)$ was significantly lower $(\mathrm{p}<0.01, \mathrm{~F}=9.42)$ than in the slough $\left(122.4 \pm 17.4\right.$ S.E. $\left.g d w \mathrm{~d}^{-1} \mathrm{~m}^{-2}, \mathrm{n}=11\right)$ during the Oct 03 sampling period. Mean flow velocities for ridge $\left(0.65 \pm 0.12\right.$ S.E. $\left.\mathrm{cm} \mathrm{sec}^{-1}\right)$ sites also were lower than those measured at slough sites $\left(0.93 \pm 0.10\right.$ S.E. $\left.\mathrm{cm} \mathrm{sec}^{-1}\right)$ during this period but these rates were not significantly different $(p=0.7, F=3.62)$. During the second sampling month 
(Dec 03), mean particulate accumulation within the ridge $\left(14.7 \pm 9.18\right.$ S.E. gdw $\left.\mathrm{d}^{-1} \mathrm{~m}^{-2}\right)$

landscape was again lower than the slough (31.7 \pm 8.76 S.E. gdw $\left.\mathrm{d}^{-1} \mathrm{~m}^{-2}\right)$, however, the means were not significantly different $(\mathrm{p}=0.19, \mathrm{~F}=1.80)$. Mean velocities for this month were significantly different $(\mathrm{p}<0.05, \mathrm{~F}=4.52)$ between the two landscapes with the ridge and the slough speeds of $0.51 \pm 0.08$ S.E. $\mathrm{cm} \mathrm{sec}^{-1}$ and $0.74 \pm 0.07$ S.E. $\mathrm{cm} \mathrm{sec}^{-1}$, respectively. Over the final sampling month (Jan 04), particulate accumulation rates for ridge (19.9 \pm 6.19 S.E. gdw d ${ }^{-1}$ $\mathrm{m}^{-2}$ ) sites were not significantly different from slough sites $\left(18.6 \pm 5.9\right.$ S.E. gdw $\left.\mathrm{d}^{-1} \mathrm{~m}^{-2}\right)$. Mean velocity was again significantly lower $(p<0.05, F=5.87)$ in the ridge landscape $(0.15 \pm 0.02$ S.E. $\left.\mathrm{cm} \mathrm{sec}^{-1}\right)$ when compared to the slough $\left(0.21 \pm 0.02\right.$ S.E. $\left.\mathrm{cm} \mathrm{sec}^{-1}\right)$.

\section{$\underline{\text { Vertical Variations in Flow and Effects of Biomass }}$}

Canopy characteristics (vegetation type, stem density, and presence or absence of periphyton and Utricularia sp.) were monitored, as well, to determine their influence on flow velocities within the Everglades slough system. These measures were coupled with the collection of vertical flow profiles to gain a better understanding of flow variability in three dimensions. Given the established relationship between flow speed and stem density in tidal and other wetland systems (Leonard \& Luther 1995; Stern et al. 2001), correlation analyses between stem density and velocity were first conducted. These analyses, however, suggested no significant correlation between the standing biomass of spike rush and flow velocity for data collected in sloughs along and near the Gumbo Limbo transect. Nonetheless, observations of dye-tracer releases suggested that the presence of biomass locally impeded flow and suggested that these impediments to flow were not distributed uniformly over either vertical or horizontal scales. 
Because of the low flow velocities and sublaminar flow conditions, turbulence (as represented by TKE), also was very low within the canopy. Burst-averaged TKE values ranged from 0.002 to $0.034 \mathrm{~J} \mathrm{~m}^{-3}$ with the highest TKE values frequently observed in areas with fewer plants. The magnitude of TKE for a given position within the water column was comparable for both sawgrass and slough sites (Figure 8); although some of the higher TKE values were observed in sawgrass. When differentiated into horizontal and vertical flow components, $\mathrm{TKE}_{\text {horiz }}\left(\mathrm{x}\right.$ and $\mathrm{y}$ components of flow) almost always exceeded $\mathrm{TKE}_{\mathrm{vert}}$. Exceptions to this occasionally occurred within $10 \mathrm{~cm}$ of the surface in the sloughs when floating vegetation, but not emergent vegetation, was present. Both $\mathrm{TKE}_{\text {horiz }}$ and $\mathrm{TKE}_{\mathrm{vert}}$ decreased with depth in the water column for both sawgrass and spike rush sites. These data suggest that although TKE was quite low in this system, turbulent energy that was present occurred in the upper 30\% of the water column (Figure 8).

Vertical flow profiles collected in the presence of vegetation deviated from a logarithmic shape (e.g. Leonard \& Luther 1995; Leonard \& Reed 2002). Unlike observations made in other wetlands characterized by monospecific stands of vegetation (Leonard \& Luther 1995), we found no consistent relationship between plant canopy architecture and flow profiles in either the sawgrass ridges or the spike rush sloughs. Where vertical changes were observed, the differences in magnitude were very subtle given the very low velocities in the system and not statistically significant.

We also investigated the extent to which the shape and magnitude of the vertical velocity profile varied at ridge/slough boundaries where vegetation transitioned from spikerush to sawgrass. To examine these variations, vertical profiles of both the $\mathrm{x}\left(\mathrm{V}_{\mathrm{x}}\right)$ and $\mathrm{y}\left(\mathrm{V}_{\mathrm{y}}\right)$ components of velocity were constructed at 2 spike rush/sawgrass site pairs. The first pair was 
located at a ridge/slough transition edge oriented parallel to the primary flow direction (Figure 1; site SC/CC1). The second site pair was located at an edge position oriented perpendicular to the primary flow direction (Figure 1; site SC/CC2). For both pairs, the shape of the $\mathrm{V}_{\mathrm{x}}$ profile in the sawgrass was consistent with the shape of the profile collected in the adjacent spike rush (Figure 9). Further, the vertically integrated mean $V_{x}$ was of similar magnitude for each pair member and oriented in the positive (down gradient) direction. The shape of the $V_{\mathrm{y}}$ profile differed between vegetation type within each pair and also differed in shape from the corresponding $\mathrm{V}_{\mathrm{x}}$ profile. The vertically averaged $V_{\mathrm{y}}$ in sawgrass was much lower than in the adjacent spike rush slough with values near zero.

Other canopy attributes (e.g. presence or absence of periphyton and Utricularia), however, also were documented during this study. We found that the shape of the velocity profile was affected by the distribution of floating aquatic plant biomass in the water column. In sawgrass flow speeds were generally lower in areas of the profile coincident with the presence of living leaves and litter even if stem densities were low (Figure 10). The presence of periphyton, especially well-developed surface mats, also affected the shape of vertical profiles collected in the spike rush sloughs (Figure 11). Where surface mats were extensive, very low velocities (which sometimes dropped below the resolution of the current meter) were observed within several centimeters of the mat. Higher flow velocities, however, usually were measured at depths below the mat as long as flows were unimpeded by the presence of Utricularia.

Utricularia, which was not commonly observed at sawgrass ridge sites, is pervasive in the spike rush sloughs and adds another structural component that affected flow velocity (Figure 11b). Velocities in regions of the flow profile coincident with Utricularia spp. tended to be reduced with higher velocities usually observed above and below this depth. 
Based our observations of the effects of periphyton and Utricularia on flow, we performed vegetative manipulations to investigate the relative effect of emergent versus submerged biomass on flow velocity within the slough. With all floating and standing biomass in place, the velocity profile exhibited an irregularly shaped profile with the highest velocity of $0.36 \mathrm{~cm} \mathrm{sec}^{-1}$ at $6 / 10^{\text {th }}$ depth in the water column (Figure 12a). The velocity near the top of this profile was lower ( $\left.0.11 \mathrm{~cm} \mathrm{sec}^{-1}\right)$. When the floating biomass (Utricularia and periphyton) was removed, thereby removing some of the baffling elements in the canopy, velocities increased to 0.94 and $0.42 \mathrm{~cm} \mathrm{sec}^{-1}$ for the near-surface and $6 / 10^{\text {th }}$ depths, respectively (Figure 12b). When the spikerush and other standing biomass was removed, the profile did not change its relative shape and depth-averaged velocity increased slightly, but not significantly. After all of the vegetation was removed, flow velocities of 1.11 and $0.42 \mathrm{~cm} \mathrm{sec}^{-1}$ were observed for the nearsurface and 6/10 ${ }^{\text {th }}$ depths, respectively (Figure 12c).

\section{DISCUSSION}

Surface flows across marshes in the Everglades exhibit many of the same features as flows across other marsh surfaces including dampened velocity fluctuations, complex vertical velocity profiles that are strongly influence by plant canopy architecture, and, for the most part, an absence of turbulence. In contrast to tidal marsh systems, however, flow speeds in the Everglades are much slower and vary in magnitude over seasonal time scales as opposed to daily or hourly time scales. The composition and distribution of particulate matter in surface waters of Everglade marshes is also quite different from what is typically encountered in tidal marsh systems. High concentrations of particulate matter are either sequestered within a few $\mathrm{cm}$ of the bed in the floc layer or occur as part of a floating periphyton mat. In both of these layers, the 
particulate matter is highly organic and frequently of neutral buoyancy. The water column between these layers is characterized by particles less than $5 \mu \mathrm{m}$ in diameter and concentrations typically less than $2 \mathrm{mg} \mathrm{L}^{-1}$. Consequently, the factors that influence flow, and hence particulate transport and deposition processes in the Everglades are somewhat different from those documented in more extensively studied tidal marsh systems.

\section{Factors affecting characteristics of surface flows}

Over the duration of this study, the speeds of surface flows in the ridge and slough landscape were positively and significantly correlated with water level in upper Shark River Slough. Water levels in this area exhibit a strong seasonality that is closely correlated to rainfall and the management of the S-12 water control structures on the Tamiami Canal (Tabb 1990; Light \& Dineen 1994). Peaks in the velocity data, which coincided with the times that the S-12 structures were open, suggest that the upstream release of water from the S-12 structures into Everglades National Park during the wet season not only increased water levels, but also increased flow rates. To further explore the relationship between water level and flow, total flow through the ridge and the slough components of the Gumbo Limbo transect was estimated for the December and January sampling periods. In December, the mean water level along the transect was $61.3 \mathrm{~cm}$ and approximately 1.3 times higher than the mean water level in January $(47.6 \mathrm{~cm})$. Flow rates in December, however, were roughly four times greater than January flow rates. In the slough sections, the estimated total flow was $4.63 \mathrm{~m}^{3} \mathrm{~s}^{-1}$ and $1.03 \mathrm{~m}^{3} \mathrm{~s}^{-1}$ in December and January, respectively. The total volume of water moving across the ridge sections was less and estimated to be $1.03 \mathrm{~m}^{3} \mathrm{~s}^{-1}$ in December and $0.26 \mathrm{~m}^{3} \mathrm{~s}^{-1}$ in January. These data suggest that even small changes in water level result in appreciable increases in downstream flow due to increases in wet cross-sectional area and increased velocity. 
Results from several in situ studies of surface flow in wetlands (e.g. Stern et al. 2001; Leonard \& Luther 1995; Leonard et al. 1995), suggest that flow speed and turbulence are very dependent on stem densities. Leonard \& Luther (1995) observed that flow speeds were greatly reduced when stem densities increased from 100 to 300 stems $\mathrm{m}^{-2}$ in a west-central Florida marsh system. We did not find a relationship between the stem density of emergent vegetation and water velocities within the sloughs in our study area. However, we did observe a strong relationship between floating vegetative biomass and flow speeds (Figure 12). A three-fold increase in mean flow, 0.23 to $0.68 \mathrm{~cm} \mathrm{sec}^{-1}$, was observed when approximately $2 \mathrm{~L}$ of floating vegetation was removed from the $1 \mathrm{~m}^{2}$ experimental plots while only a small increase in mean flow, 0.68 to $0.76 \mathrm{~cm} \mathrm{sec}^{-1}$, was observed when the remaining emergent spike rush stems were removed. Prior to clearing, approximately $0.47 \%$ of the total experimental plot volume was occupied by biomass resulting in a volumetric flux of about $0.0012 \mathrm{~m}^{3} \mathrm{~s}^{-1}$ per linear meter. After all of the floating vegetation was removed, the volumetric flux of water increased by a factor of 3.5. The volumetric flux through the sampling plot area increased to roughly $0.004 \mathrm{~m}^{3} \mathrm{~s}^{-1}$ per linear meter when the remaining spike rush was removed. These results seem to suggest that less water may be moving down-slough when Utricularia and periphyton are present. This conclusion, however, is based on only a few manipulations conducted over small spatial scales and should be validated by additional measurements or by manipulations conducted over larger areas.

The velocity profiles measured within the no vegetation and the spike rush only treatments exhibited gradual linear increases with distance above the bottom. This shape may reflect the low number of measured heights along the profile and a lack of measurements taken across the sediment boundary layer. Nonetheless, this shape is consistent with profiles measured 
in lacustrine macrophyte beds (Alisma gramineum) subject to similar linear velocities (i.e. less than $3 \mathrm{~cm} \mathrm{~s}^{-1}$ ) and consisting of a comparable number of point measurements (Vermaat et al. 2000) and to some European tidal marsh canopies characterized by abundant emergent vegetation or very slow surface velocities (Shi et al. 1995; Neumeier \& Ciavola 2004). These results suggest when flow speeds are very slow, either due to high spatial density of vegetation or due to low ambient flow velocities, and the vertical distribution of biomass is fairly uniform, that the vertical velocity profile is linear despite differences in vegetation type or environmental setting (e.g. lacustrine, tidal, or other).

In wetland environments, microscale turbulence is a controlling factor over particle settling and dispersion processes and tends to be produced primarily by stem wakes (Nepf 1999). One way to assess the potential presence of microscale turbulence is by calculating the Reynolds number $\left(\operatorname{Re}_{d}\right)$ for flow around individual stems. Stem Reynolds numbers $\left(\operatorname{Re}_{d}=V d / v\right.$; where $v$ is the kinematic viscosity and d is stem diameter) were determined for the range of observed velocities using mean stem diameters for sawgrass and both species of spike rush present in the study area. In sawgrass, which exhibits a slightly larger stem diameter but experienced lower flow speeds, $\mathrm{Re}_{\mathrm{d}}$ ranged from 23 to 167 . In spike rush, $\mathrm{Re}_{\mathrm{d}}$ ranged from 3 to 24 and 15 to 157 for E. elongata and E. cellulosa, respectively, with the difference due to differences in mean stem diameter between the species. These values were one to two orders of magnitude greater than those reported by Saiers et al. (2003) for spike rush subjected to much slower velocities in a surface-water flume in upper Shark River Slough, but still largely fell below the critical value $\left(\mathrm{Re}_{\mathrm{d}}>200\right)$ required for development of stem-generated turbulence (Nepf 1999; Wu et al. 1999). These values were consistent, however, with the range of $\mathrm{Re}_{\mathrm{d}}$ values reported by Lee et al. (2004) for flume simulations through sawgrass and indicate that flows are essentially laminar 
to sublaminar in both sawgrass ridges and spike rush sloughs. Although not directly observed during this study, there are several realistic scenarios that would result in $\mathrm{Re}_{\mathrm{d}}$ values large enough to indicate stem-generated turbulence. The first would be to increase flow velocities to 3 to $5 \mathrm{~cm} \mathrm{~s}^{-1}$ which would elevate $\operatorname{Re}_{\mathrm{d}}$ values above 200 in stands of E. cellulosa. Another potential mechanism for wake produced turbulence may be the interaction of flows with plant elements with greater diameters such as vegetation clumps or stems covered by periphyton. Stems coated with periphyton “sweaters” or extremely closely spaced vegetation, may exhibit larger effective stem frontal areas per unit flow volume, thereby increasing the potential for wake produced turbulence. The low levels of turbulence indicated by the $\mathrm{Re}_{\mathrm{d}}$ calculations reported here, however, were consistent with the direct measures of turbulence (as indicated by TKE) collected at various positions in the water column. TKE throughout the water column was low and exhibited a decrease with depth below the water surface in sawgrass and in spike rush when surface periphyton mats were absent. When present, surface periphyton may suppress surface oscillations, such as those generated by wind (Lee et al. 2004), and inhibit turbulence development just as near surface velocities were reduced in the presence of periphyton during this study (Figure 11; Figure 12).

\section{$\underline{\text { Factors affecting particulate transport }}$}

In the ridge and slough landscape, most of the particulate matter is a neutral density flocculent-like organic material present near the soil surface. Above this near-bottom floc layer, the concentration of total suspended solids is quite low and consists of highly organic particles with mean grain sizes on the order of $3.3 \mu \mathrm{m}$ (Bazante et al. 2003). Based on the Stokes settling relationship, the vertical (z-component) velocity would need to be less than about $3.5 \times 10^{-4} \mathrm{~cm}$ $\mathrm{s}^{-1}$ (a value below the resolution of the equipment used in this study) for relatively low density 
particles of this size to settle. When we were able to resolve the vertical velocity component, we found that it usually exceeded this value.

The results of this study suggest that conditions are not conducive to the settlement of the fine, low density particles suspended in the upper water column in the study area in spite of the low Re and low levels of turbulence. Nonetheless, material did accumulate in the sediment collection cups deployed during this study thereby suggesting that material is being lost from the water column albeit mediated by some other process(es) than direct settling of suspended particles in the size range of 3 to $5 \mu \mathrm{m}$. Saiers et al. (2004) suggest that the transport of small, colloidal type particles in the Everglades is limited to a few tens of meters before these particles are removed from the water column via binding to periphyton coatings on plant stems. A similar phenomenon has been observed by Stumpf (1983) in tidal salt marshes and suggested to play an important role in facilitating the transfer of fine sediments to the marsh surface when the living plant dies. This process, however, was not directly observed during this study. Another potential, and similar, removal mechanism of suspended particulates might be scavenging by floating biomass, especially the more filamentous forms of Utricularia. Whether intercepted by periphyton or other floating biomass, the removal rates of suspended particles from the upper water column would be expected to vary seasonally with maximum impact coincident with periods of peak productivity. Once attached, the transfer of adhered particles to the sediment surface, or at least to the lower water column, is facilitated when 1) the periphyton or other floating biomass degrades into settleable particles, and 2) when the periphyton or floating biomass (or pieces thereof) and attached particles are caught on other obstacles to flow such as stems or topographic highs. In these instances, material from the upper water column either becomes incorporated in the near-bed "floc” layer and moves gradually down-slough as bedload, 
or, is subsequently transferred to the sediment surface when the standing biomass dies or when water levels drastically decrease (i.e. dry season or dry-down events).

The sediment accumulation data provide qualitative evidence in support of the aforementioned removal mechanisms. The sediment traps used in this study sample material from the water column in two ways: collecting settleable material falling vertically from the overlying water column and entraining suspended material when flowing water passes over the edges of the cup. Thus, the accumulation rates presented here represent several potential inputs. Particle settling from the upper water column is probably the least significant source of material given the low concentration of suspended material in the upper water column, particle attributes and ambient flow conditions. In situ production of settleable material, such as the formation of detrital particles or production of floc material, likely plays a larger role; an assumption corroborated by our observations of fibrous material retained in the sediment traps (Wood, 2005). It is most likely; however, that the accumulation rates actually reflect particle availability or particle fluxes in the water column approximately $8 \mathrm{~cm}$ above the bed (height of the sediment traps) resulting form a combination of both in situ production, advective transport and, possibly, near-bed disturbance of the floc layer.

If the accumulation data are viewed as a measure of particle availability and if other mechanisms besides direct settling are invoked to explain transfer of suspended particles to the bed, the data presented here are consistent with the conceptual landscape development model of infilling sloughs and decreased deposition on ridges (SCT 2003) currently postulated for the lower Everglades. In this study, the sawgrass ridges usually exhibited lower water levels, lower velocities, lower accumulation rates (i.e. particle availability) and less periphyton and floating biomass compared to the sloughs. Consequently, the potential for deposition or long-term 
accumulation on the ridges is much less than in the sloughs where material availability is enhanced by a combination of higher water levels, higher velocities, and greater periphyton and floc production. Further, if it can be assumed that material is incorporated on the surface during low water levels or dry down events, the low or near zero velocities, reduced near bed TKE, and lack of vertical shear precludes the development of sufficient shear stresses at the bed to induce scour and resuspension. As a result, any material that is deposited on or near the bed remains there when subjected to the range of physical conditions documented during this study. There are, however, several processes that may cause the floc material located near the bed to be resuspended higher in the water column. One is biological activity, such as sunfish nesting, which was observed near sediment traps during this study. Once higher in the water column, the resuspended material would be transported down-slough until able to settle or until intercepted, as described above. Another process is the occurrence of extreme events characterized by higher water levels, increased flow velocities, and, possibly, increased wind, which might produce conditions sufficient to mix the floc material higher in the water column or even cause scour of the marsh surface. Although infrequent, high energy events also may provide a mechanism to transport floc, periphyton, and Utricularia to the interior of sawgrass ridges, which when trapped, would be deposited on the ridges. Thus, future studies should focus on acquiring hydrologic and particulate data during extreme events.

\section{CONCLUSIONS}

Understanding the processes regulating the transport of particulate matter is critical to anticipating depositional patterns in freshwater wetlands. This is especially relevant to the Everglades where the degradation of the ridge and slough landscape is believed to be due, in 
part, to disruptions in flow patterns and changes in sediment deposition (SCT 2003). As a result, current efforts are underway to develop numerical hydrodynamic models that can simulate surface flows and particle settling as part of Everglades restoration activities (e.g. Lee et al. 2004; Saiers et al. 2003). These modeling efforts, like those developed for constructed wetlands, reveal the need to accurately describe plant/flow interactions due to factors such as plant density, plant form and dimension, plant rigidity, degree of submergence, and spatial heterogeneity of plant distribution (Jadhav \& Buchberger 1995; Stern et al. 2001; Lee et al. 2004). Until recently, however, most models incorporated only those parameters associated with the permanent vascular plant canopy (i.e. stem density, stem diameter, leaf area indices etc.). Current Everglades’ model efforts (e.g. Lee et al. 2004; Saiers et al. 2003), have concluded that other features of the canopy such as dead plant litter and periphyton also exert significant control over vegetative drag and dispersion. Our results corroborate these observations and suggest that future research should focus on developing expressions that describe changes in flow regime due to the presence of periphyton coatings, surface periphyton mats, and litter. In addition, our field data strongly indicate that future modeling efforts must also take the presence of floating biomass, such as Utricularia, into consideration as has been recently attempted by Harvey et al. (2005).

Our conclusions can be summarized as follows:

- Flow velocities in the slough sites were greater than velocities measured on ridges;

- Flow speeds were positively and significantly correlated with water level thereby enhancing particulate transport in sloughs relative to ridges especially during peak flow periods;

- The distribution of biomass in the water column, including floating plants and periphyton, affects velocity magnitude and shape of vertical profiles; 
- The presence of surface periphyton and Utricularia exert greater control over flow characteristics than plant type (i.e. sawgrass or spike rush);

- At higher velocities, wakes may develop around stems with larger diameters due to periphyton coatings and at lower velocities wake structure may form around clumps of smaller diameter stems. Although not directly observed during this study, wake development may enhance dispersion and help account for our observations of velocity heterogeneity within an individual sough or ridge.

\section{ACKNOWLEDGEMENTS}

This project was funded by the Everglades National Park, U.S. National Park Service and received additional support from the National Science Foundation through the FCE LTER Program (DEB-9910514) and the Center for Marine Science at the University of North Carolina Wilmington. The authors gratefully acknowledge the assistance of the following individuals: Adam Wood, Jose Bazante, Damon Rondeau, Stuart Stothoff, Tim Grahl, Phil Bayer, Dan Aten, and also the staff of ENP. 


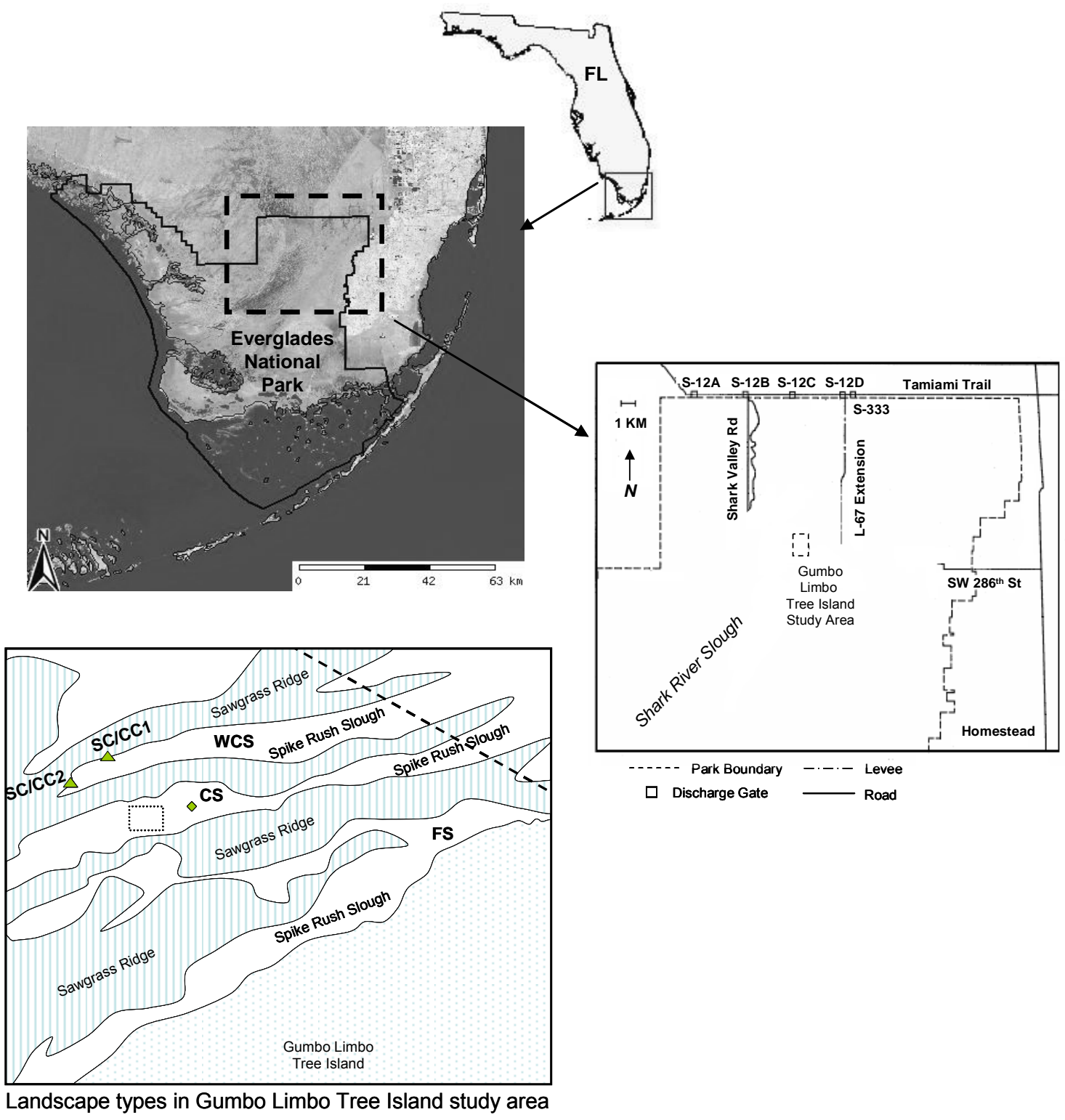

Figure 1. Leonard et al. 


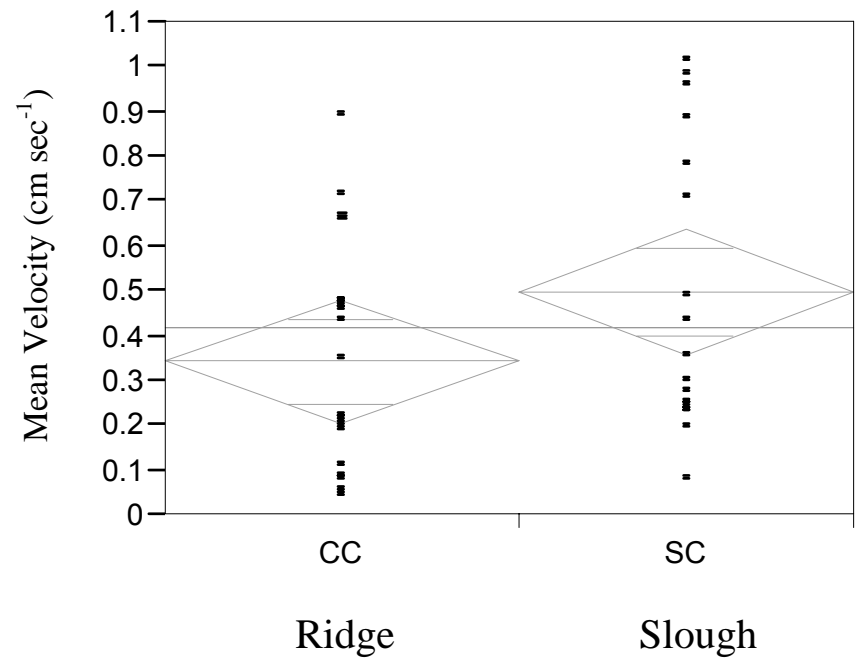

Figure 2. Leonard et al. 

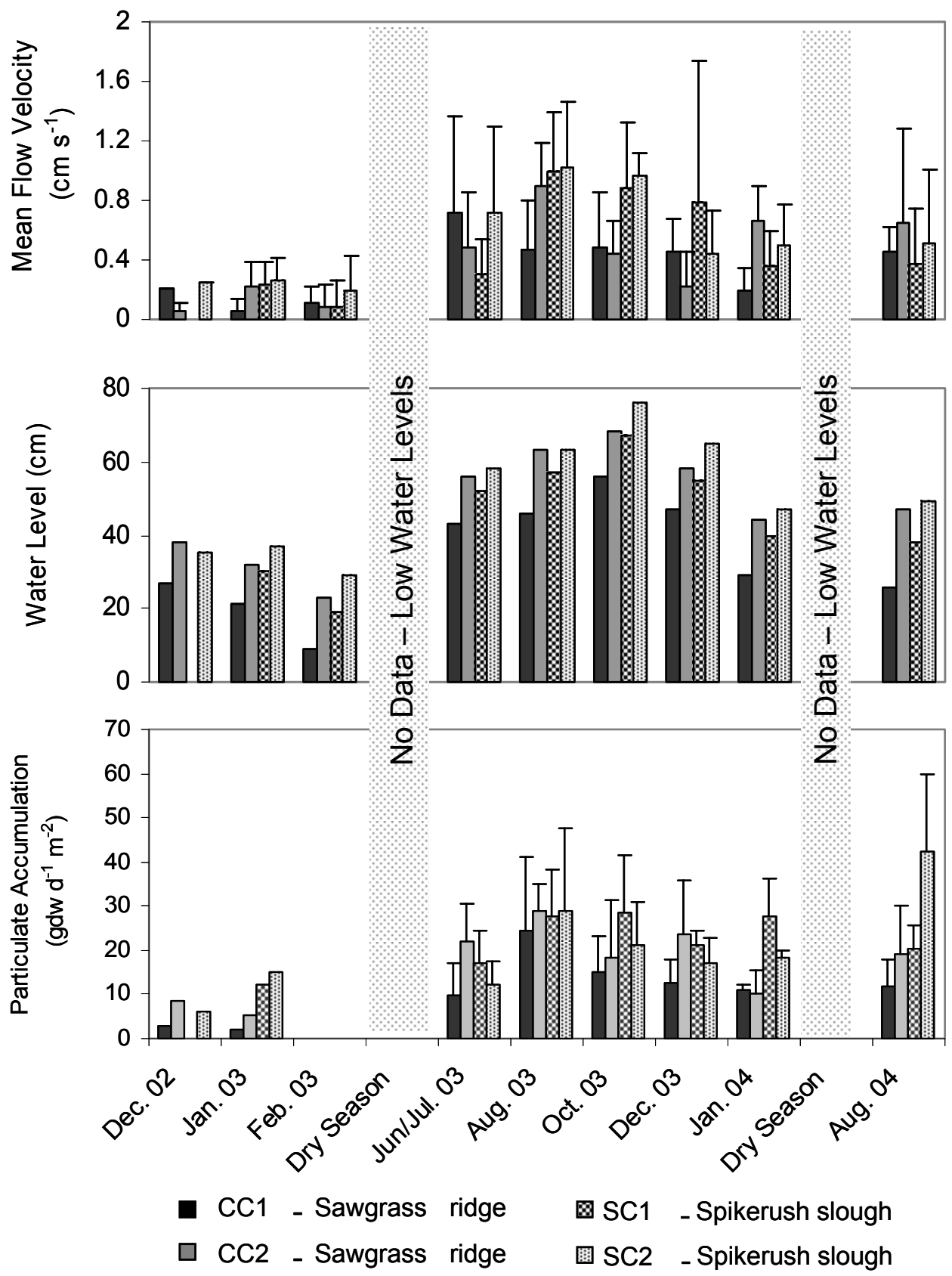

Figure 3. Leonard et al. 


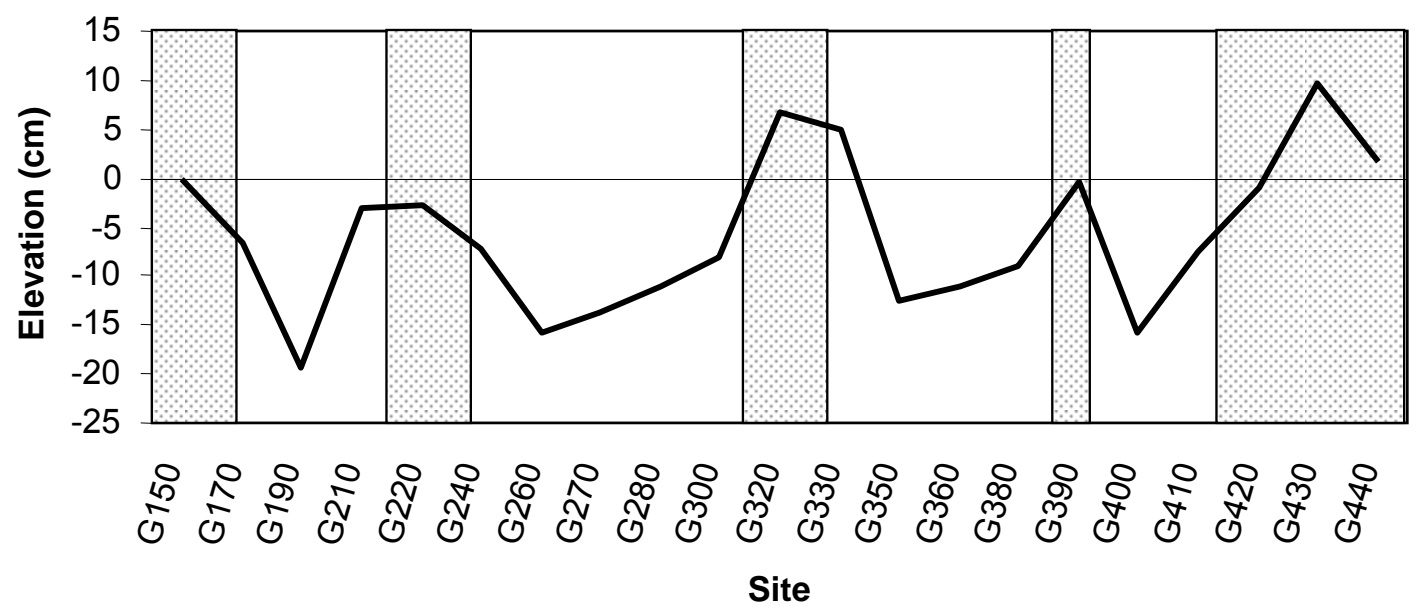

Figure 4. Leonard et al. 


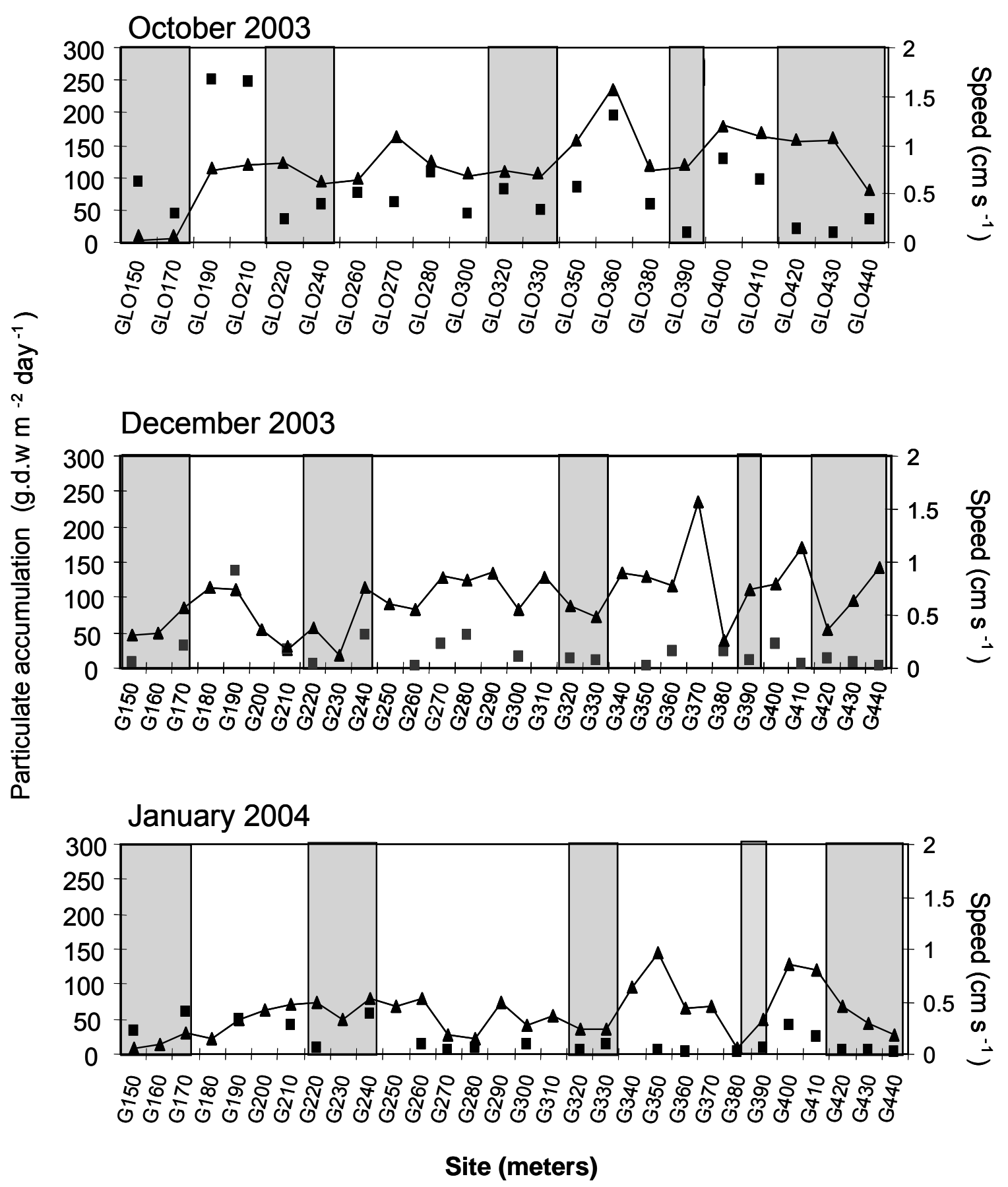

Figure 5. Leonard et al. 


\section{Slough 1--FS}

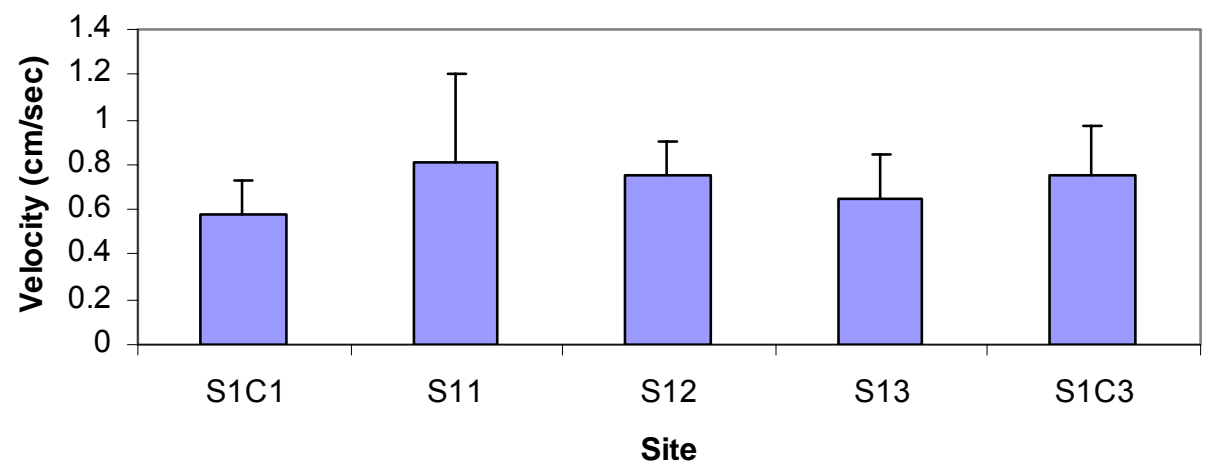

Slough 2--CS

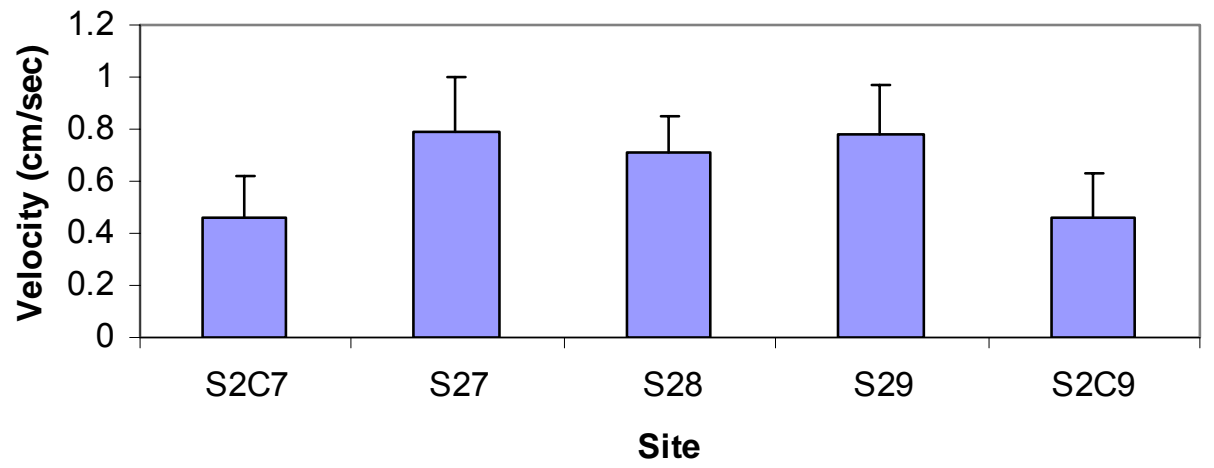

Slough 3--WCS

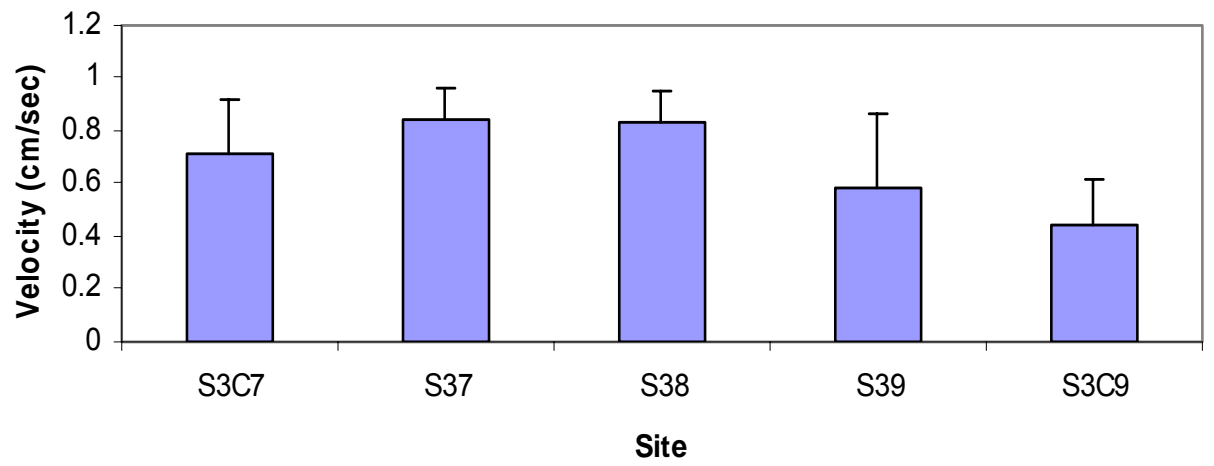

Sawgrass

Slough

Sawgrass

Figure 6. Leonard et al. 

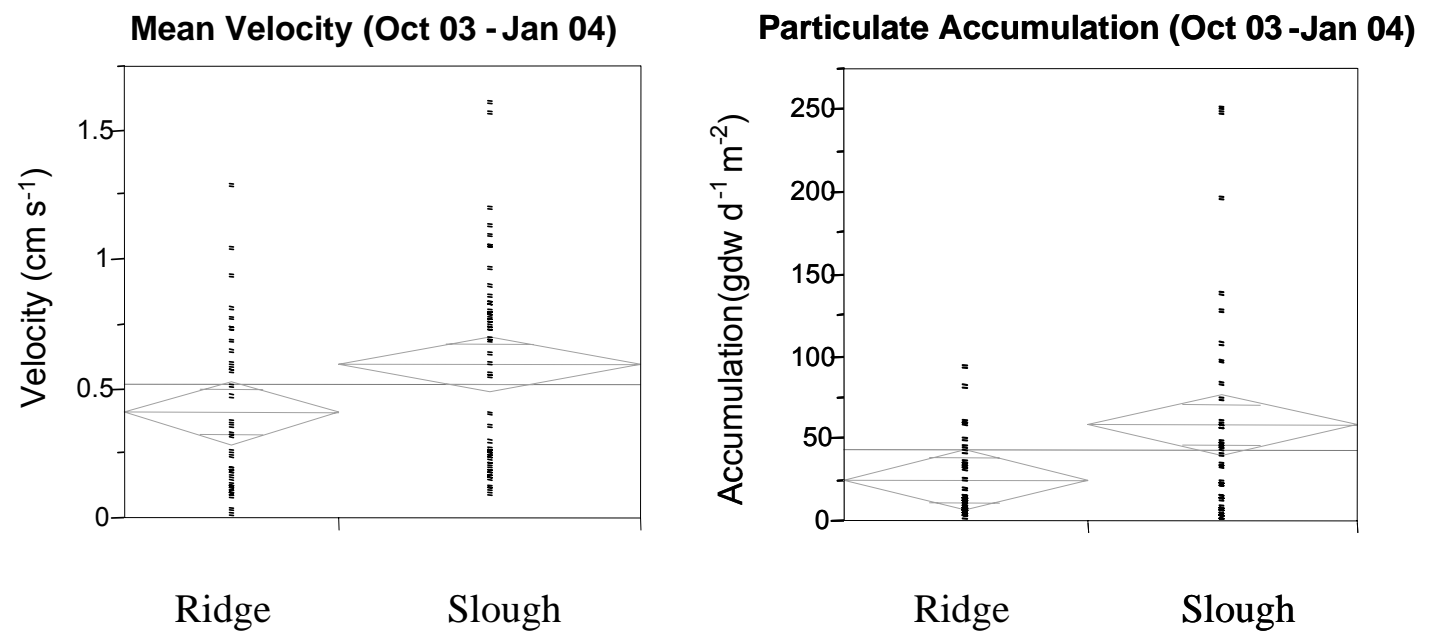

Figure 7. Leonard et al. 

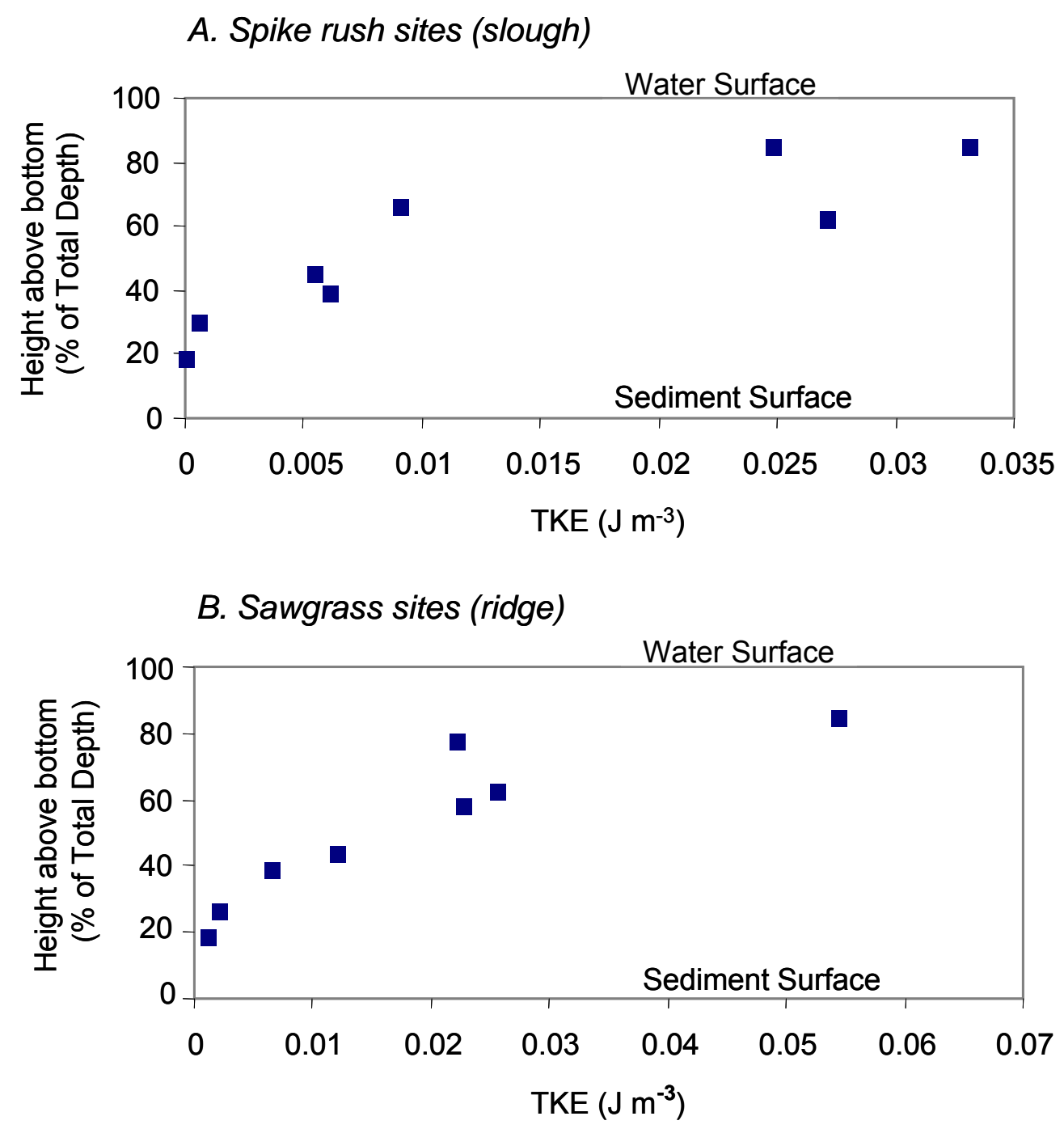

Figure 8. Leonard et al. 
A. Sawgrass ridge (parallel to flow) Mean Vx $\left(\mathrm{cm} \mathrm{s}^{-1}\right)$

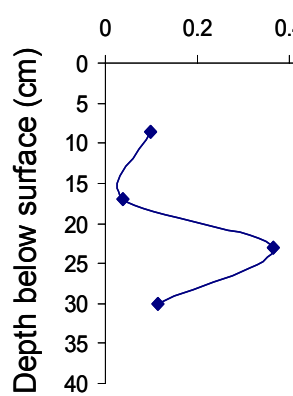

Mean $\mathrm{Vy}\left(\mathrm{cm} \mathrm{s}^{-1}\right)$
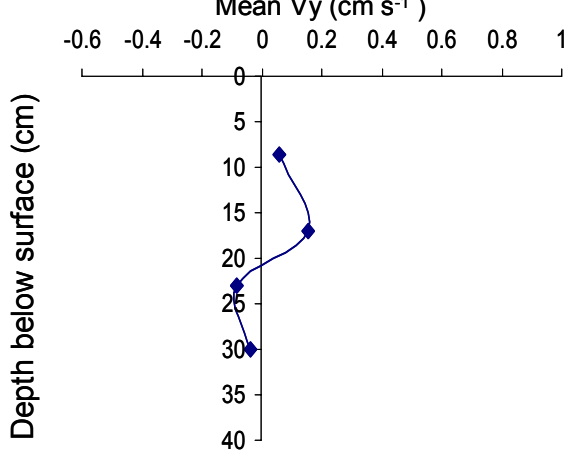

B. Sawgrass ridge (normal to flow)
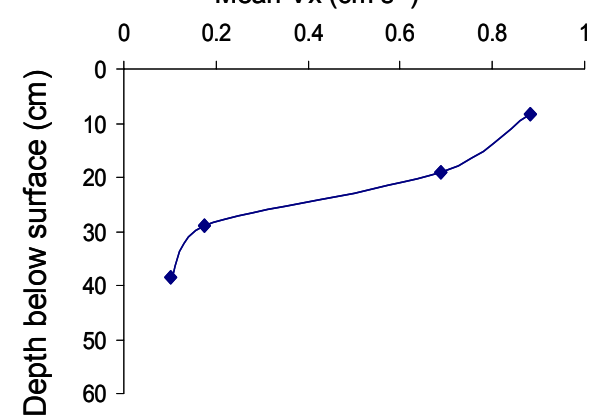

Mean $\mathrm{Vy}\left(\mathrm{cm} \mathrm{s}^{-1}\right)$

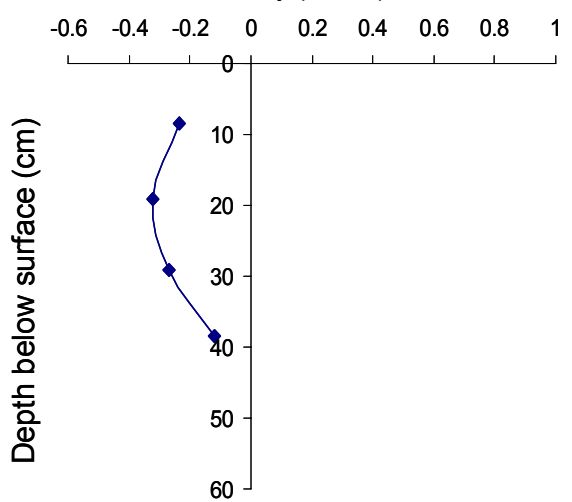

Spike rush slough (parallel)

Mean Vx $\left(\mathrm{cm} \mathrm{s}^{-1}\right)$
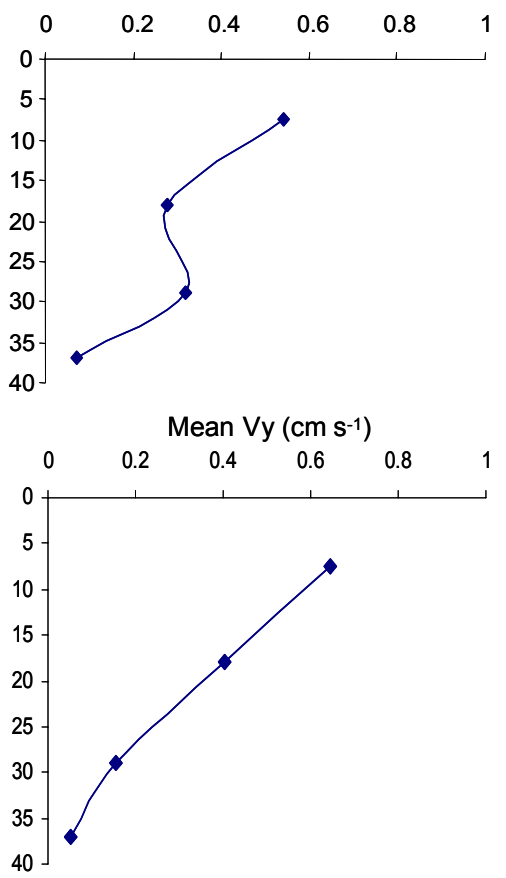

Spike rush slough (normal to flow) Mean $\mathrm{Vx}\left(\mathrm{cm} \mathrm{s}^{-1}\right)$
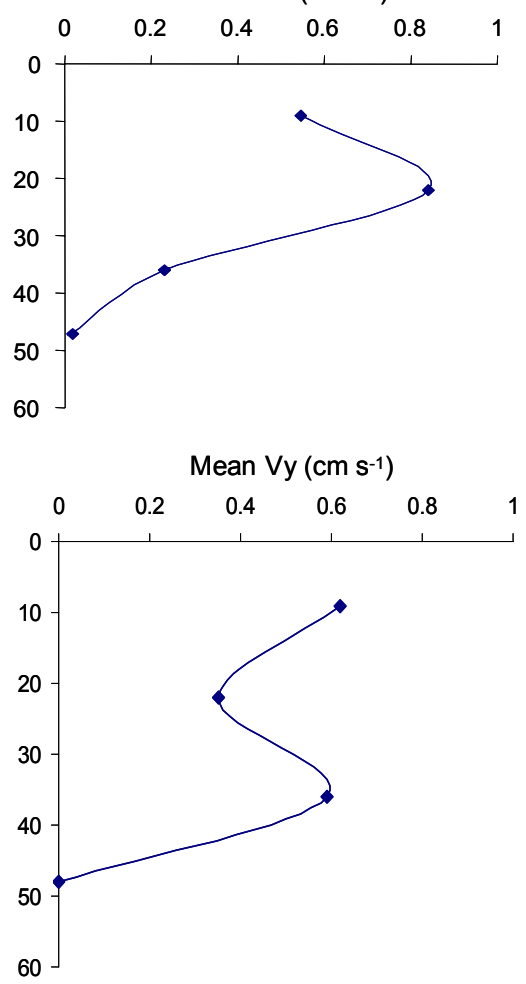

Figure 9. Leonard et al. 


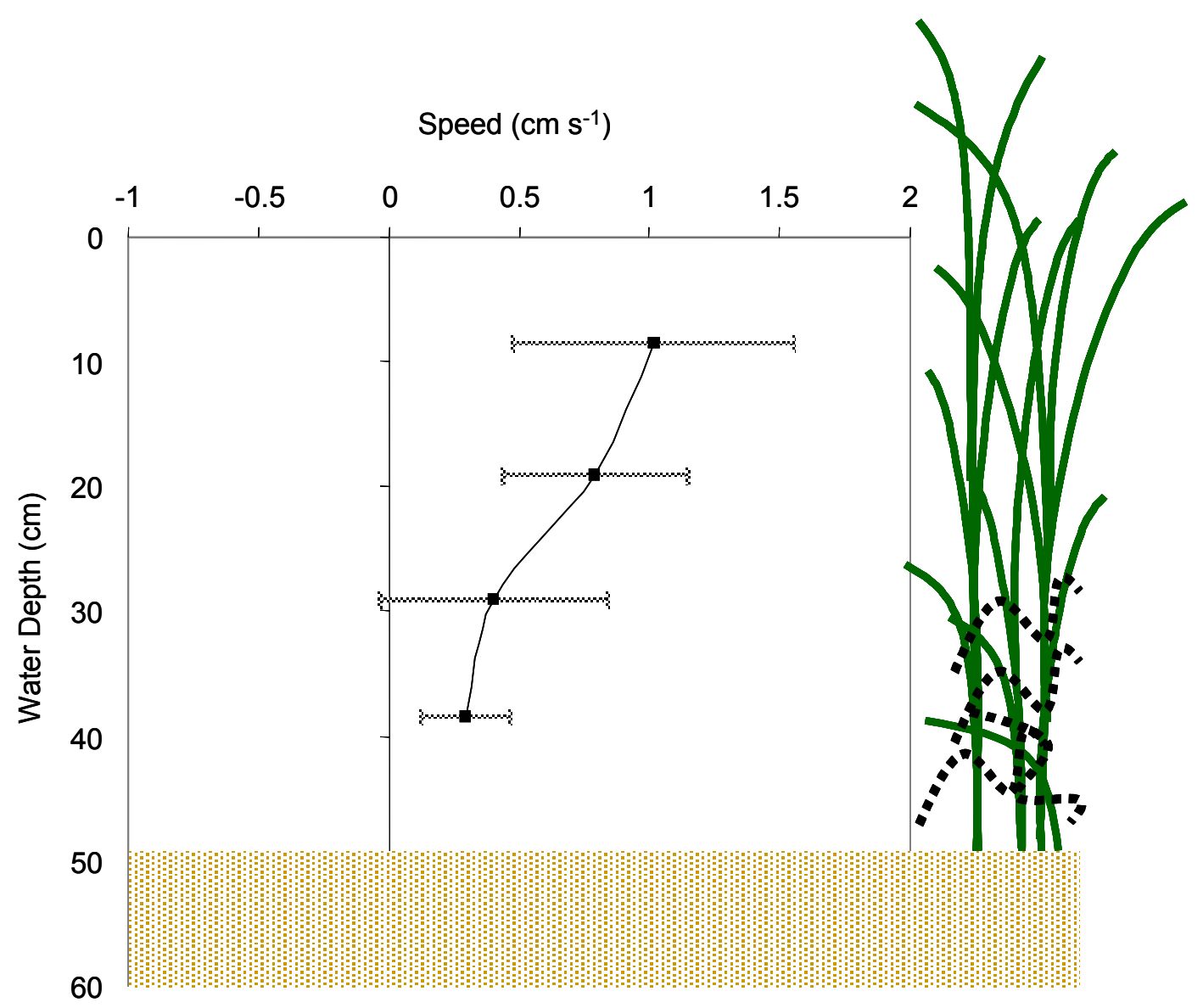

Figure 10. Leonard et al. 
A.

Speed $\left(\mathrm{cm} \mathrm{s}^{-1}\right)$

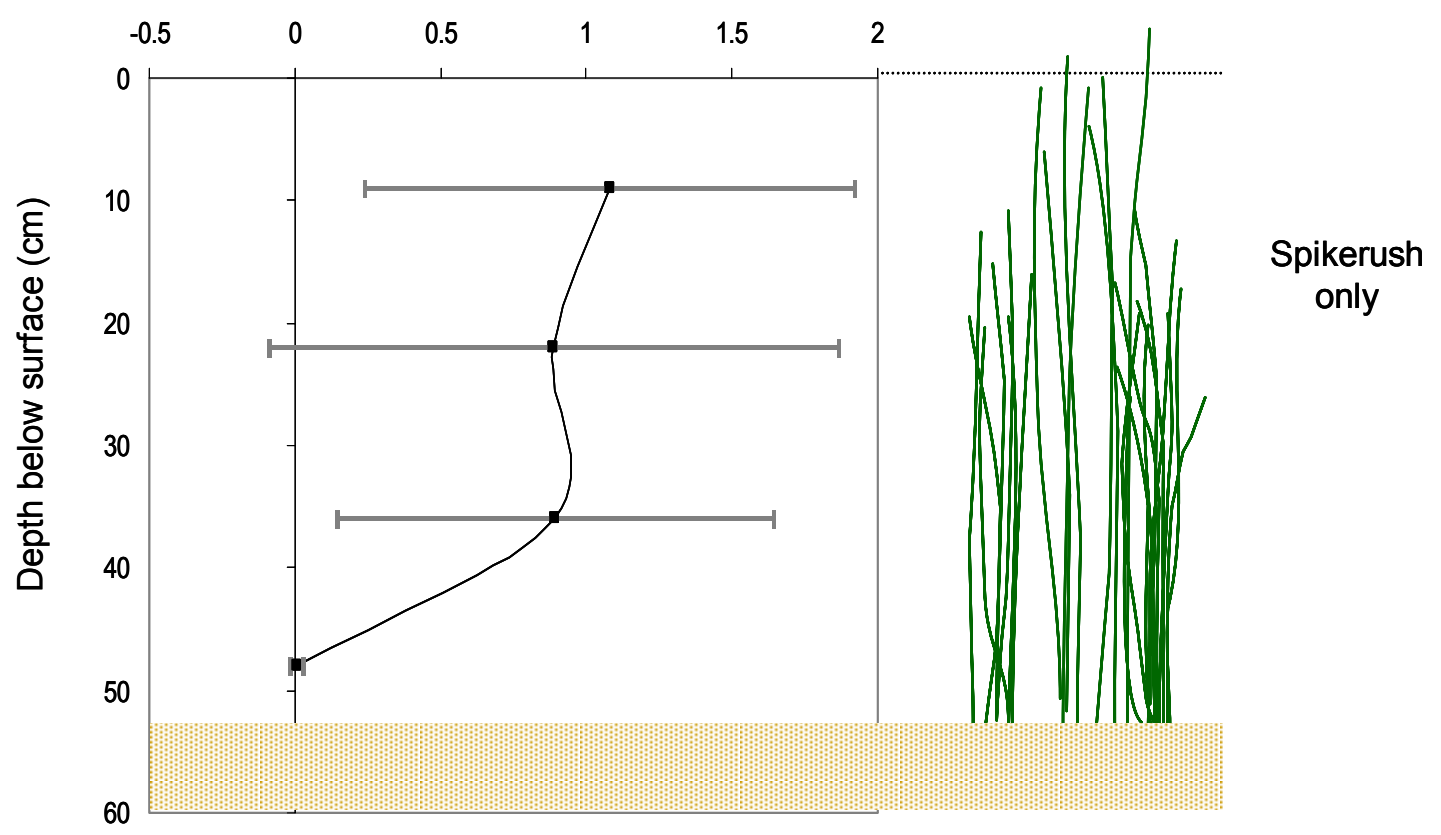

B.

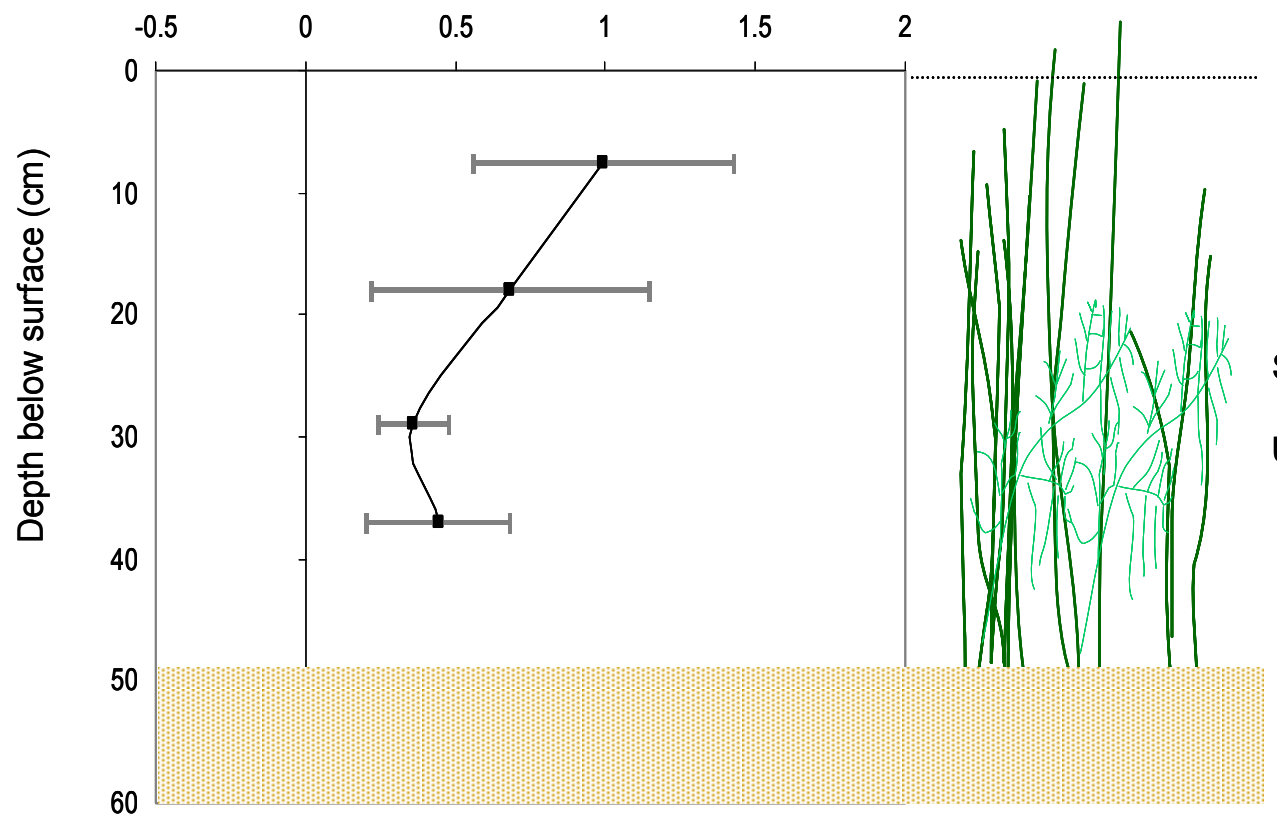

Spikerush And Utricularia spp.

Figure 11. Leonard et al. 
C.

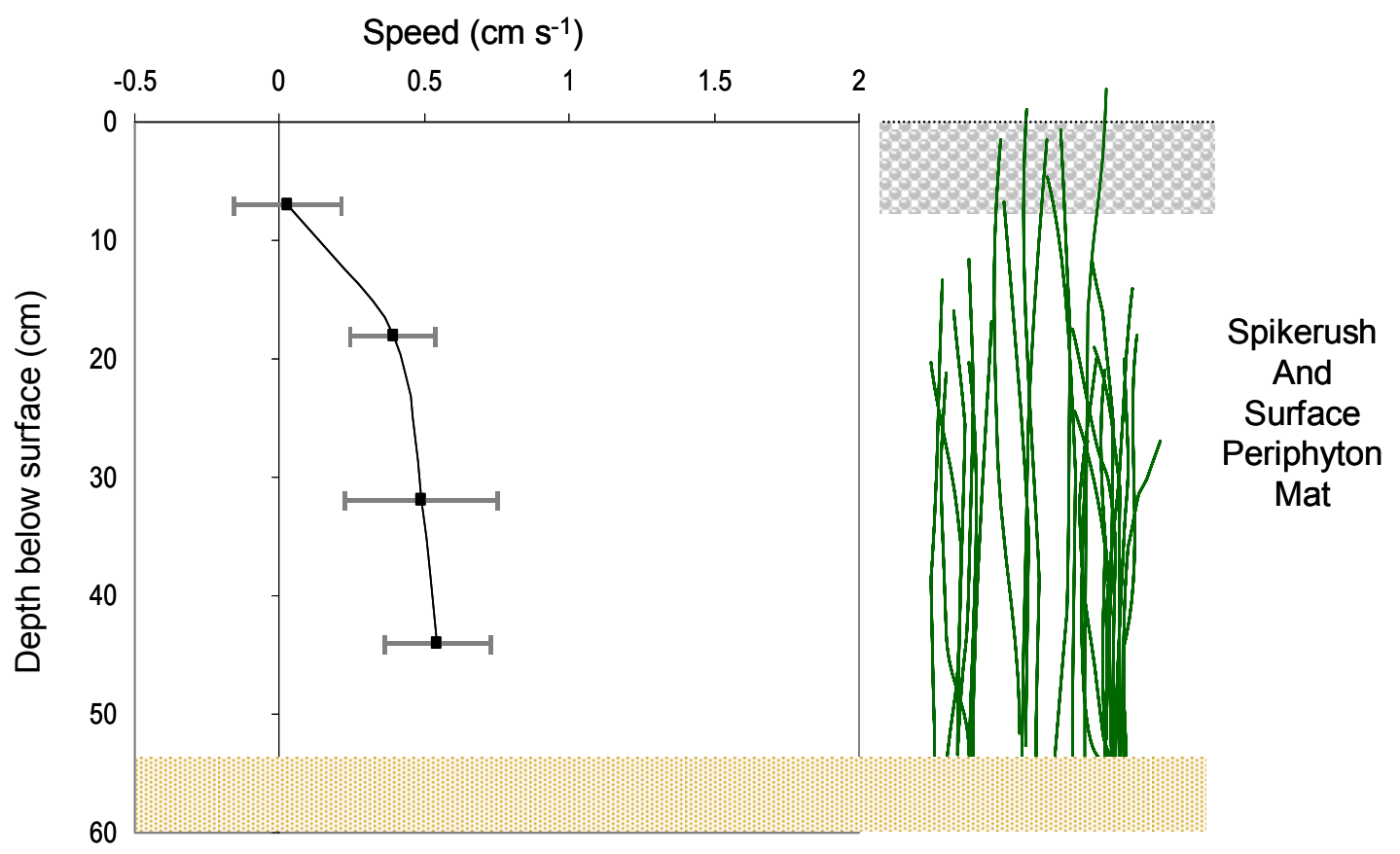

Figure 11 cont'd. Leonard et al. 
A.
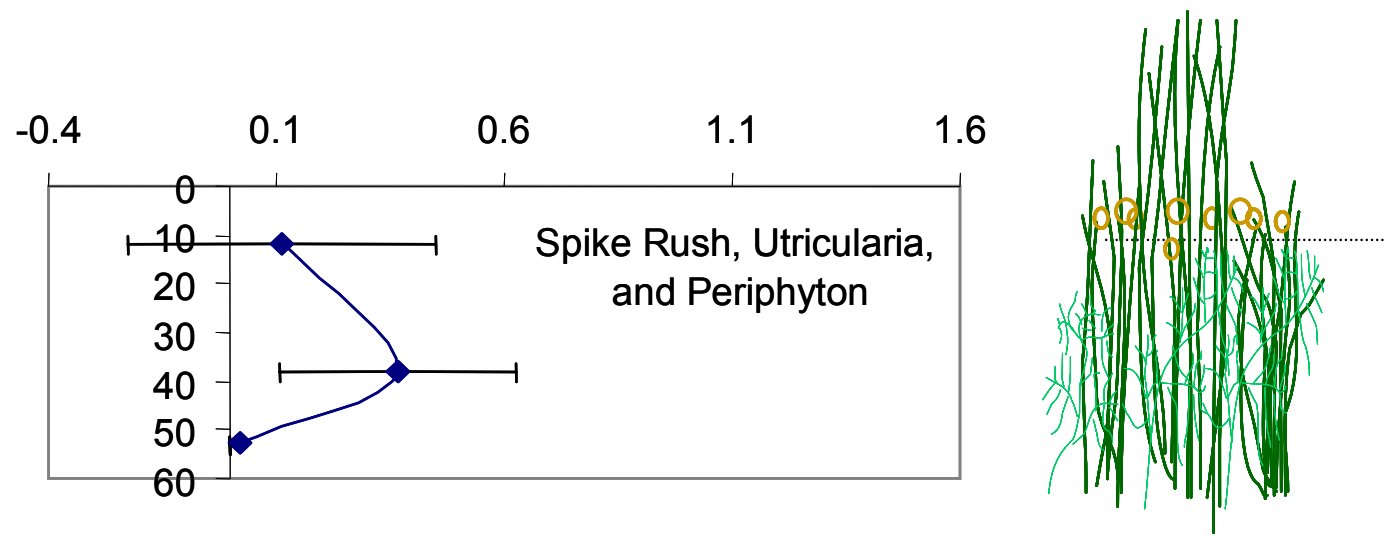

B.
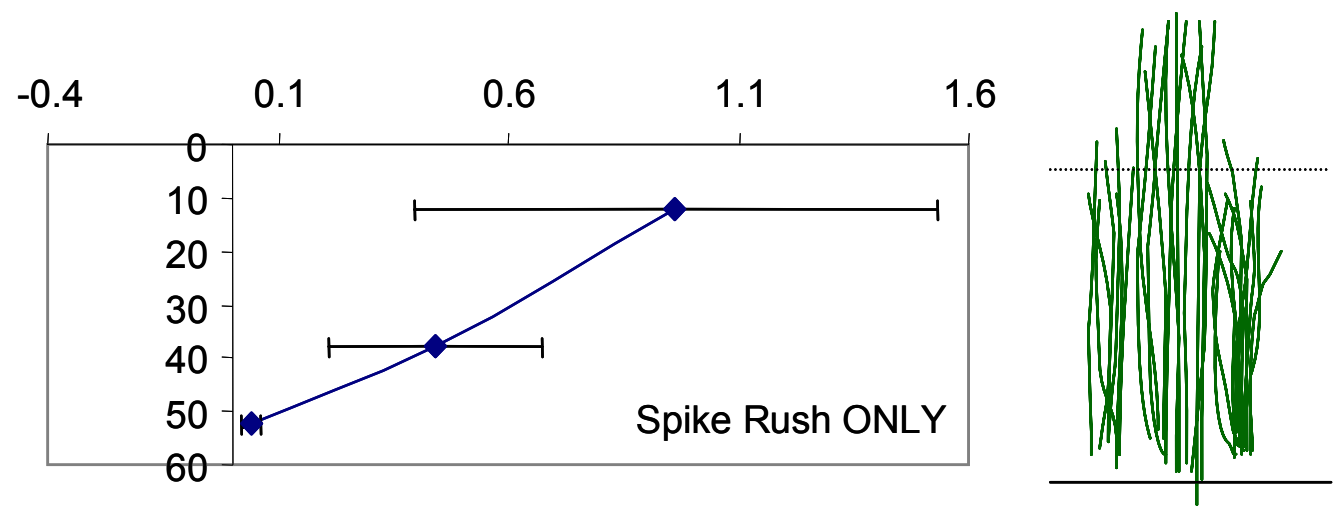

C.

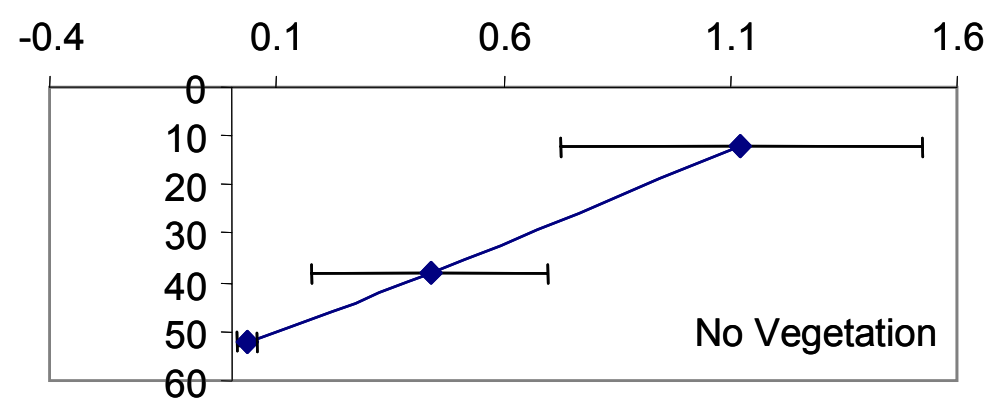

Figure 12. Leonard et al. 
Figure Captions.

Figure 1. Location map of study area in upper Shark River Slough, Everglades National Park (A). All data were collected in the vicinity of a tree island locally known as Gumbo Limbo. Panel B is a illustration of environment types within the study area and also shows the locations of specific sampling sites (triangles and diamonds), the Gumbo Limbo sampling transect (dashed line), and the area where the clearing experiments were conducted (dashed square). WCS, CS, and FS refer to specific sloughs described in Figure 7.

Figure 2. Burst-averaged flow velocities measured at sawgrass ridge sites and spike rush slough sites between Jun 03 and Jan 04. The center line across the widest section of each diamond is the mean for each group calculated from all bi-monthly sampling events. The top and bottom of the diamond correspond to the $95 \%$ confidence interval while the width of the diamond is proportional to the number of replicates. The remaining lines in the diamonds are overlap lines. Where these lines overlap between the two diamonds in a panel, a t-test indicated no significant difference between the means at $\mathrm{p}<0.05$.

Figure 3. Mean bi-monthly flow velocities, water levels, and particulate accumulation rates measured at selected sawgrass ridge sites (CC) and spike rush slough sites (SC) over the entire study duration. Sampling sites are shown on Figure 1.

Figure 4. Topographic profile of the Gumbo Limbo Transect. Shaded areas indicate areas along the transect consisting of sawgrass ridge and white areas indicate spike rush slough.

Figure 5. Flow velocity, water level, and particulate collection along the Gumbo Limbo transect for Oct 03, Dec 03, and Jan 04. Shaded areas indicate positions of sawgrass ridges.

Figure 6. Mean (x,y,z) flow velocities measured across 3 sloughs near Gumbo Limbo (see Figure 1). Transects were initiated just inside the sawgrass at one edge of the slough and completed just inside the sawgrass on the other edge. The other measures were taken at distances of $0.25,0.5$ and 0.75 the width of the slough

Figure 7. Flow velocity and rate of particulate accumulation in sediment traps deployed in sloughs and ridges along the Gumbo Limbo transect for deployments between Oct 03 and Jan 04. The center line across the widest section of each diamond is the mean for each group calculated from all bi-monthly sampling events. The top and bottom of the diamond correspond to the 95\% confidence interval while the width of the diamond is proportional to the number of replicates. The remaining lines in the diamonds are overlap lines. Where these lines overlap between the two diamonds in a panel, a t-test indicated no significant difference between the means at $\mathrm{p}<0.05$.

Figure 8. Burst-averaged TKE values measured at selected spike rush and sawgrass ridge sites in June 2004. In order to evaluate changes in TKE among sites with different total water depths, the vertical axis on this figure is presented as relative height above the sediment surface and expressed as a percentage of total water depth. 
Figure 9. Vertical velocity profiles constructed using the $\mathrm{x}$ and $\mathrm{y}$ components of velocity for sites located at the edge of spike rush to sawgrass transitions. Panel A shows data collected at an edge located parallel to the dominant flow direction (triangle SC/CC1 on Figure 1). Panel B shows data collected at a transition located normal to dominant flow direction (triangle SC/CC2 on Figure 1).

Figure 10. Representative vertical velocity profile collected in sawgrass areas in June 2003. Error bars denote standard deviation of velocity sampled over a 30 second sampling burst. The stippled region indicates the position of the bed at the time of sampling. The heavy dashed lines indicate regions where standing litter was present.

Figure 11. Vertical velocity profiles collected in spike rush sloughs in the presence and absence of floating Utricularia and well-developed periphyton mats. Panel A shows a typical flow profile collected in an area with no periphyton mat and devoid of Utricularia. Panel B shows a flow profile collected in an area where Utricularia was present in the canopy but no periphyton mat existed. Panel C shows a flow profiled collected in an area with a well established periphyton mat, but no Utricularia.

Figure 12. Representative vertical velocity profiles collected for a series of biomass clearing experiments in spike rush sloughs. Panel A shows velocity measurements collected in the presence of spike rush, surface periphyton and Utricularia (i.e. no biomass removed). Panel B shows velocity measurements after removing Utricularia and periphyton in a $1 \mathrm{~m}^{2}$ region surrounding the measurement site. Panel $\mathrm{C}$ shows velocity measurements after all vegetation had been removed. Error bars indicate +/- one standard deviation of the mean velocity for a one minute sampling burst. 


\section{References Cited}

Bazante, J.H.M., H. Solo-Gabriele, M. Ross, D. Childers, S. Mitchell-Bruker, \& L. Leonard, 2003. Water Velocity and Suspended Solids Concentrations in the Proximity of Tree islands in Everglades National Park. Proceedings of the Joint Conference on the Science and Restoration of the Greater Everglades and Florida Bay Ecosystem, "From Kissimmee to the Keys". April 13-18, 2003. Palm Harbor, Florida, pp. 19-20.

Bedford B.L., 1996. The need to define hydrological equivalence at the landscape scale for freshwater wetland mitigation. Ecological Applications 6: 57-68.

Mitchell-Bruker, S., J. Bazante, D. Childers, L. Leonard, M. Ross, H. Solo-Gabriele, R. Snow \& S. Stothoff, 2005. Effect of Hydrology on Everglades Ridge and Slough Community. Report to Everglades National Park, Homestead, FL.

Chimney M.J. \& G. Goforth, 2001. Environmental impacts to the Everglades ecosystem: a historical perspective and restoration strategies. Water Science and Technology 44: 93-100.

Christiansen, T., P.L. Wiberg \& T.G. Milligan, 2000. Flow and sediment transport on a tidal salt marsh surface. Estuarine, Coastal and Shelf Science 50: 315-331.

Davis, S. M. \& J. C. Ogden, 1997. Everglades: the ecosystem and its restoration. St. Lucie Press, Boca Raton.

Harvey, J.W., J.E. Saiers \& J.T. Newlin, 2005. Solute transport and storage mechanisms in wetlands of the Everglades, south Florida. Water Resources Research, 41: 1-14.

Jadhav, R. S. \& S.G. Buchberger, 1995. Effects of vegetation on flow through free water surface wetlands. Ecological Engineering 5: 481-496.

Kadlec, R. H., 1990. Overland flow in wetlands: Vegetation resistance. Journal of Hydraulic Engineering 116: 691-706.

Kundu, P. K., 1990. Fluid mechanics, Academic Press, San Diego.

Kushlan, J.A., 1993. Freshwater wetlands. Pages 74-127 in M.S. Dennison and J.F. Berry. Wetlands: guide to science, law, and technology. Noyes Publications, Park Ridge, New Jersey.

Lee, J. K., L.C. Roig, H.L. Jenter \& H.M. Visser, 2004. Drag coefficients for modeling flow through emergent vegetation in the Florida Everglades. Ecological Engineering 22: 237-248.

Leonard, L.A., 1997. Controls of sediment transport and deposition in an incised mainland marsh basin, southeastern North Carolina. Wetlands 17:263-274. 
Leonard, L. A., A.C. Hine \& M.E. Luther, 1995. Surficial sediment transport and deposition processes in a Juncus roemerianus marsh, West-central Florida. Journal of Coastal Research 11: 322-336.

Leonard, L. A. \& D.J. Reed, 2002. Hydrodynamics and sediment transport through tidal marsh canopies. Journal of Coastal Research SI 36: 459-469.

Leonard, L. A. \& M.E. Luther, 1995. Flow hydrodynamics in tidal marsh canopies. Limnology and Oceanography 40: 1474-1484.

Nepf, H. M., 1999. Drag, turbulence, and diffusion in flow through emergent vegetation. Water Resources Research 35: 479-489.

Nepf, H. M. \& E.R. Vivoni, 2000. Flow structure in depth limited, vegetated flow. Journal of Geophysical Research 105/C12: 28547-28557.

Nepf, H. M., J.A. Sullivan \& R.A. Zavistoski, 1997. A model for diffusion within emergent vegetation. Limnology and Oceanography 42: 1735-1745.

Neumeier, U. \& P. Ciavola, 2004. Flow resistance and associated sedimentary processes in a Spartina maritima salt marsh. Journal of Coastal Research 20: 435-447.

Saiers, J. E., J.W. Harvey \& S.E. Mylon, 2003. Surface-water transport of suspended matter through wetland vegetation of the Florida Everglades. Geophysical Research Letters 30(19): 15 .

Science Coordination Team (SCT), 2003. The Role of Flow in the Everglades Ridge and Slough Landscape. South Florida Ecosystem Restoration Working Group. Approved by the SCT: January 14, 2003.

Shi, Z., J.S. Pethick \& K. Pye, 1995. Flow structure in and above the various heights of a saltmarsh canopy: a laboratory flume study. Journal of Coastal Research 11: 1204-1209.

Shi, Z., J.S. Pethick, \& K. Pye, 1996. Velocity profiles in a salt marsh canopy. Geo-Marine Letters 16: 319-323.

Shi, Z., L.J. Hamilton \& E. Wolanski, 2000. Near-bed currents and suspended sediment transport in saltmarsh canopies. Journal of Coastal Research 16: 909-914.

Somes, N. L. G., W.A. Bishop \& T.H.F. Wong, 1999. Numerical simulation of wetland hydrodynamics. Environment International 25: 773-779.

Stern, D.A., R. Khanbilvardi, J.C. Alair \& W. Richardson, 2001. Description of flow through a natural wetland using dye tracer tests. Ecological Engineering 18: 173-184. 
Stumpf, R. P., 1983. The process of sedimentation on the surface of a salt marsh. Estuarine, Coastal and Shelf Science 17: 495-508.

Tabb, D., 1990. Hydroperiod conditions of key environmental indicators of Everglades National Park and adjacent east Everglades area as guide to selection of an optimum water plan for Everglades National Park, Florida. Tropical BioIndustries, Inc., Miami.

Vermaat, J. E., L. Santamaria \& P.J. Roos, 2000. Water flow across and sediment trapping by submerged macrophyte beds of contrasting growth form. Archiv für Hydrobiologie 148: 549562.

Wood, A., 2005. Dynamics of detrital particulate organic material in the ridge and slough landscape of the Everglades. Masters Thesis, Florida International University.

Wu, F.C., H.W. Shen \& Y.J. Chou, 1999. Variation of roughness for unsubmerged and submerged vegetation. Journal of Hydraulic Engineering 125: 934-942. 